\title{
The relationship between cultural values, cultural intelligence and negotiation styles
}

Pre-print version accepted for publication in the Journal of Business Research

Andrea Caputo (Corresponding author)

University of Lincoln, Lincoln International Business School

Brayford Pool, LN6 7TS Lincoln, United Kingdom acaputo@lincoln.ac.uk

ORCID: 0000-0003-2498-182X

Oluremi B. Ayoko

The University of Queensland, UQ Business School

39 Blair Dr, St Lucia QLD 4067, Australia

r.ayoko@business.uq.edu.au

Nii Amoo

Leeds Business School

Leeds Beckett University

The Rose Bowl, Portland Gate, LS1 3HB, Leeds, United Kingdom

n.amoo@leedsbeckett.ac.uk

Charlott Menke

Otto-von-Guericke University

Universitätspl. 2, 39106 Magdeburg, Germany

charlott.menke@ovgu.de

\begin{abstract}
Working environments become increasingly culturally diverse and managers, employees and people at large are often required to engage in cross-cultural negotiations. In this regard, it becomes important for negotiators to develop the ability to recognize cultural differences and adapt their negotiation styles to the cultural contingencies they face. This study examines the influence of cultural intelligence on the relationship between cultural values and the individual preferences for a given negotiation style. Our results show that cultural values (e.g. power distance, uncertainty avoidance, collectivism and masculinity) have a direct influence on negotiation styles as well as an indirect effect, which is mediated through cultural intelligence. The study highlights the importance of cultural values and cultural intelligence on negotiation styles and contributes to the research and practice of negotiations.
\end{abstract}

Keywords: cultural values, cultural intelligence, negotiation styles, competition, cooperation, cultural differences 


\section{The relationship between cultural values, cultural intelligence and negotiation styles}

\section{Introduction}

The ability to negotiate is critical for successful interactions in today's multicultural workplaces. Negotiation is "a process of potentially opportunistic interaction by which two or more parties, with some apparent conflict, seek to do better through jointly decided action than they could otherwise" (Lax and Sebenius,1986 p. 11). Consequently, management scholars have put much effort in investigating the process of negotiating across different cultures and how cultural differences impact negotiations (Gunia, Brett, \& Gelfand, 2016; Ogliastri \& Quintanilla, 2016). They find that successful cross-cultural negotiation requires a good understanding of the differences in cultural values and behaviors (Adair \& Brett, 2005; Groves, Feyerherm, \& Gu, 2015; Imai \& Gelfand, 2010). However, prior research also finds that intercultural exchanges in negotiations suffer from higher challenges (Imai \& Gelfand, 2010), lower outcomes (e.g., Brett \& Okumura, 1998), and communication difficulties (e.g., Liu, Chua, \& Stahl, 2010). Yet, negotiating is one of the most practiced joint decision-making processes at different organizational levels and functions (Caputo, 2016; Ogliastri \& Quintanilla, 2016). Hence, the choice of an appropriate negotiation style balancing a competing (or aggressive) style with a collaborating (or cooperating) style - is important to negotiate effectively across cultures (Imai \& Gelfand, 2010). There exists an extensive body of comparative research on cross-cultural negotiations but scholars call for more integrated approaches and beyond the mere demonstration of cultural differences in negotiation styles (Groves et al., 2015; Imai \& Gelfand, 2010). In particular, negotiation styles may not only be affected by culture, but also by, yet unknown, individual characteristics (Elfenbein, 2015). Building on previous research findings, our study responds to the calls for more integrated research (Groves et al., 2015; Imai \& Gelfand, 2010) and aims at filling this gap in the literature through the examination of how the selection of a negotiation style is affected by individual's different cultural values (CV) and cultural intelligence (CQ), which is a "person's capability for successful adaptation to new cultural settings" (Earley \& Ang, 2003, p. 7).

In line with recent research in conflict management (Caputo, Ayoko, \& Amoo, 2018), we argue that in cross-cultural settings negotiators must be able to recognize cultural differences and adapt their negotiation style to the cultural contingencies required for being successful. Hence, it is important to understand the relation between cultural values and an individual's preference for a certain negotiation style. More importantly, it is critical to gauge the impact of cultural intelligence on this relationship. In this respect, our study makes several theoretical contributions. First, we contribute to the existing literature on the determinants of negotiation styles by examining the direct effects of cultural values and CQ on two particular negotiation styles, i.e., the cooperative and the competitive negotiation style. Second, we also investigate the mediating role of CQ on the relation between cultural values and negotiation styles. Third, we expand the research on CQ by operationalizing it as a second order composite construct, answering the 
call for studies by Ott and Mchailova (2018) to further investigate CQ's role as a mediator variable.

\section{Theoretical framework and research hypotheses}

\subsection{Negotiation styles}

As previously mentioned, Lax and Sebenius (1986) define negotiation as a process of potentially opportunistic interaction by which two or more parties with some apparent conflict seek to do better through jointly decided action. Similarly, Lewicki, Saunders and Barry (2014) define a negotiation situation by the following characteristics: a) two or more independent parties; b) a conflict of interest; c) the choice of all parties to negotiate to achieve better outcomes; d) a process of give and take, e) tangible and intangible issues to negotiate, and f) an interest in the relationship with the other parties. Both definitions of negotiations are grounded in the dual concern model (Pruitt \& Rubin, 1986). Accordingly, negotiating individuals face two dual concerns along a continuum ranging from the self-concern, i.e. to pursue and defend their own interests, and the other-concern, i.e. to foster or uphold a positive relationship with the other parties. When negotiators lean more toward the self-concern, they will put their own interest first, which results in a fixed-sum situation (Pruitt \& Rubin, 1986). In this respect, negotiators will claim value for themselves through competitive behaviors (Lax \& Sebenius, 1986). In contrast, when negotiators are inclined more toward the other-concern, their interest in the relationship with the other parties will make them engage in value creating and cooperative approaches (Lax \& Sebenius, 1986). Thus, negotiators are found to swing between cooperation and competition and even do so during the same negotiation (Olekalns $\&$ Smith, 2003) because they often have mixed motives (Kong, Dirks, \& Ferrin, 2014), despite their general tendency toward either end of the self/other concern continuum (De Dreu \& Boles, 1998).

Following this dichotomy, this study will concentrate on the competitive and cooperative negotiation styles. On the one hand, the competitive negotiation styles involve the use of distributive or combative tactics, such as threats, false promises, misrepresentation of positions, bluffing, selective disclosure, and sometimes deception to force concessions from the other parties (Lewicki \& Robinson, 1998). Negotiators, who adopt competitive negotiation styles, assume that the negotiation is a fixed-sum game and that a gain of a party is a loss for the other (win-lose). On the other hand, the cooperative negotiation style, also referred to as integrative or problem-solving style, involves the use of tactics to increase cooperation and information exchange with the other party. Negotiators approach the negotiation as a problem to solve and see the process as joint decision-making. They honestly discuss the interests, preferences and needs of the all parties and try to find a solution that mutually benefits all (win-win) (Harinck \& De Dreu, 2004).

\subsection{Negotiation Styles and Cultural Values}

Prior research has revealed that individuals differ in their general preferences as well as in their 
negotiation preferences and that such differences are culture specific (Elfenbein, 2015; Gunkel, Schlaegel, \& Taras, 2016; Sharma, Bottom, \& Elfenbein, 2013). However, not all individuals within one culture are alike. For example, in a collectivistic society, there might be individuals who are allocentric (i.e. they express characteristics of collectivism) and others who are idiocentric (i.e. they express characteristics of individualism). These within-cultural variations, which occur at the individual level, may have a substantial impact on how people negotiate. While several studies have investigated the impact of cultural differences on negotiation processes and outcomes (e.g., Adair \& Brett, 2005; Gelfand et al., 2013; Gelfand \& Christakopoulou, 1999; Vieregge \& Quick, 2011), they have mostly focused on the comparison between different cultures. We argue that a major shortcoming of this previous research in this field is the assumption that only nationality determines cultural values whilst overlooking within-country variations. Additionally, such previous research has failed to provide a systematic approach to the relationship between cultural values and certain negotiation styles (Vieregge \& Quick, 2011). In line with recent research that highlights the importance of individual differences in negotiation (e.g., Elfenbein, 2015; Sharma et al., 2013), we believe that measuring cultural values at the individual level allows for a more nuanced understanding of the individual differences in negotiation styles within and across cultures.

Past research provides several prominent frameworks to understand and measure cultural values. For example, the GLOBE study (House, Hanges, Javidan, Dorfman, \& Gupta, 2004) investigates culture and leadership in 61 nations and identified nine cultural competencies: performance orientation, future orientation, assertiveness, power distance, humane orientation, institutional collectivism, in-group collectivism, uncertainty avoidance, and gender egalitarianism (House et al., 2004). Similarly, Schwartz (2006) analyzed data from 73 countries and finds seven distinct cultural value orientations (i.e., harmony, mastery, embeddedness, affective autonomy, intellectual autonomy, and egalitarianism, and hierarchy) that he groups into three contrasting cultural value dimensions.

In contrast to these two frameworks, the work by Hofstede $(1980,2001)$ includes fewer cultural dimensions and, therefore, has been criticized for oversimplifying culture. He surveyed employees of one single multinational corporation and first identified five cultural dimensions (power distance, uncertainty avoidance, individualism/collectivism, masculinity/femininity, and long term/short term orientation) and from subsequent research includes one additional dimension (indulgence/restraint). While some scholars argue that Hofstede's original sample fails to capture how culture evolved over time and neglects withincountry cultural differences (e.g., Kirkman, Lowe, \& Gibson, 2006), it is still the most frequently applied framework by researchers, particularly in negotiation (Adair \& Brett, 2005; Adair, Hideg, \& Spence, 2013; Kirkman et al., 2006; Vieregge \& Quick, 2011). For this reason, we employ Hofstede's (1980) cultural framework and follow his definition of culture as "the collective programming of the mind that distinguishes the members of one group or category of people from others" (p. 25).

As a collective phenomenon, culture resides in more or less conscious values and norms (Hofstede, 
2001). The cultural dimensions framework by Hofstede (1980) became popular for several reasons. First, its dimensions not only cover but also extend other major conceptualizations of culture. For example, Kirkman et al. (2006) reviewed research on culture published after Hofstede's (1980) framework and concluded that large-scale studies have de facto maintained or extended Hofstede's findings rather than contradicted. In addition, Hofstede's framework is empirically derived whereas several other cultural constructs remain theoretical (Yoo, Donthu, \& Lenartowicz, 2011). Additionally, his research provides quantitative data on cultural values and, hence, allows researchers to easily differentiate between cultures (Yoo et al., 2011). Accordingly, scholars across different research disciplines have applied and validated Hofstede's framework and find it to be the most important theory of culture (Kirkman et al., 2006; Yoo et al., 2011). Finally, adopting this intensively used framework allows researchers to compare and relate their findings to previous and future research on the subject.

Even though Hofstede's framework of cultural dimensions provides numerous benefits for researchers, using national culture to explain individual differences and behaviors would be faulty (Yoo et al., 2011) because national culture mirrors generalized values, norms, beliefs, and behaviors based on exogenous regional demographics and, hence, is similar to stereotyping. There might be variations in cultural values across the individuals within one regional area. Thus, researchers, managers, and policy makers should account for these specific cultural variations before drawing conclusions, inferring behavioral expectations, and making decisions. To date, it is even more imperative to measure culture at the individual level because Hofstede's data were collected decades ago when organizational environments were still somewhat representative of national characteristics. However, due to increased mobility and modern communication systems, the composition of people in one country and their values have strongly changed and one can no longer assume that people with the same national boundaries share the same cultural values. Accordingly, scholars request future studies to address these limitations of Hofstede's cultural value framework (e.g., Tu, 2014). To overcome these limitations, Yoo et al. (2011) developed an individual-level measure of Hofstede's five cultural dimensions. This measure allows scholars to directly assess the cultural values of an individual, rather than inferring them from national-level scores provided by Hofstede's research (e.g., Caputo et al., 2018). For the purpose of this study, we use this approach and measure cultural values at the individual level and, thereby, we contribute to research on individual differences in negotiations. In the following, we elaborate more on Hofstede's cultural values and derive our first hypotheses about how the cultural values relate to both negotiation styles described earlier (i.e., the cooperative and the competitive negotiation style).

Power Distance. Hofstede (2001) defines Power Distance as the extent to which the less powerful members of an organization expect and accept that power is distributed unequally (Hofstede, 2001). In other words, Power Distance describes the degree to which both followers and leaders disapprove or endorse power inequalities in their society. On the one hand, people with low Power Distance cultural values 
consider equal opportunities and general equality to be highly important and desirable. Even though people may have a different status in society, the use of power should be based on ethical criteria in order to be legitimate (Hofstede, 2011). On the other hand, people with high Power Distance cultural values consider inequality as fundamentally good. They believe that everyone has a place in the hierarchy of society that needs no further justification.

Only few studies examine the impact of Power Distance on an individual's preference of negotiation styles. For example, negotiators from power distant cultures (Asian) tend to apply more powerrelated strategies, while negotiators from egalitarian cultures (European) prefer negotiation behaviors that spread power (Graf, Koeszegi, \& Pesendorfer, 2012). We argue that high Power Distance suggests that both the strong and the weak individuals will accept the unequal distribution of power distribution on the society. Therefore, the more powerful individuals would most likely make use of their power and show dominant behavior over the weak, believing in such approach to be legitimate. In contrast, the weak individuals in cultures with high Power Distance will accept the dominant behavior of the more powerful people. Similarly, we argue that individuals in cultures with lower Power Distance will rather use cooperative negotiation styles. Thus, they will not accept dominant behavior but, instead, consider others at an equal level and, therefore, show solidarity. Since inequalities are undesirable to individuals with low Power Distance values, negotiation partners will strive to find outcomes that are beneficial for all involved parties. In order to achieve such outcomes, they need to cooperate. Thus:

Hypothesis 1a: Power Distance is positively related to a competitive style of negotiation. Hypothesis 1b: Power Distance is negatively related to a cooperative style of negotiation.

Uncertainty Avoidance. Uncertainty Avoidance relates to the extent to which society tolerates ambiguity and the degree to which its members feel comfortable in ambiguous, uncertain, and unstructured situations (Hofstede, 2001). People characterized by low values of Uncertainty Avoidance tend to accept and even embrace uncertainty in their lives and perceive less stress and anxiety. They also tolerate if people deviate from expectations, favor new ideas, dislike rules, and are not afraid of change. On the contrary, individuals with high Uncertainty Avoidance are uncomfortable when change happens. Consequently, they experience higher levels of stress and anxiety and more often express their need for clarity and structure. They need to trust and have confidence in the other party at the negotiation table to reduce the risk in the relationship (Graham, Kim, Lin, \& Robinson, 1988). As such, transparency is valued and expected. In negotiations, individuals expressing higher Uncertainty Avoidance are expected to share information and communicate more openly during the negotiation, tending to adopt a cooperative style to obtain the desired outcome and preserve the relationship with the other party (House et al., 2004; Saorín-Iborra \& Cubillo, 2016). They will rather avoid competition and prefer to cooperate with the other parties involved, to limit the risk associated with the higher perception of uncertainty (Tversky \& Kahneman, 1974). Conversely, it is expected that individuals with low Uncertainty Avoidance will more often engage in competitive and 
riskier conflict management and negotiation styles. For example, Saorín-Iborra and Cubillo (2016) found that the higher the Uncertainty Avoidance the greater the use of time pressure aggressive tactics are used by negotiators. Thus:

Hypothesis 2a: Uncertainty Avoidance is negatively related to a competitive style of negotiation. Hypothesis 2b: Uncertainty Avoidance is positively related to a cooperative style of negotiation.

Collectivism vs. Individualism. Collectivism describes how individuals are integrated into primary groups. In contrast to individuals from individualistic cultures, people living in cultures with high collectivistic values have a great preference for maintaining harmony. They favor the members of their own in-group over out-group members. The relationship ties between these individuals are close and group members takes care of each other (Hofstede, 2001). Past empirical research on the influence of Collectivism on the choice of negotiation styles is contradictory and, instead of having measured the degree of Collectivism, researchers inferred it from the individual's nationality. Evidence exists that collectivism is negatively related to pretending, deceiving, and lying tactics (Banai et al., 2014), which, in turn, are associated with competitive negotiation styles (Lewicki et al., 2014). There is further evidence that individuals from collectivistic cultures less often chose unethically and competitive negotiation styles compared to people from individualistic cultures (Rivers \& Volkema, 2013). This finding is in line with Hofstede's (2001) description that individuals embedded in collectivistic cultures have a stronger consciousness for the group. Thus, such individuals think "we" and behave in favor of the group, which is necessary to foster integrative negotiations (Cai, Wilson, \& Drake, 2000; Caputo, 2016; Traavik, 2011), and we expect that such individuals will prefer the cooperative style in negotiations. For example, on the other end of the spectrum, negotiators adhering to individualistic cultural values were expected to be engaging with more competitive tactics, such as time pressure (Saorín-Iborra \& Cubillo, 2016), are affected by the fixed-pie bias, meaning they tend to interpret the negotiation in a competitive way (Gelfand \& Christakopoulou, 1999), and are considered to be more concerned with their own interests (Brett \& Okumura, 1998). Thus:

Hypothesis 3a: Collectivism is negatively related to a competitive style of negotiation. Hypothesis 3b: Collectivism is positively related to a cooperative style of negotiation.

Masculinity vs. Femininity. As Hofstede (1980, 2001) argued, the cultural dimension of Masculinity-Femininity describes the division between emotional roles and gender roles. On the one hand, in masculine cultures men are thought to be assertive and ambitious, whereas women are more caring. Such cultures place a greater emphasis on work than on family and admire the strong. Consequently, individuals with masculine cultural values tend to be more assertive and competitive, and roles of achievement, control, and power are constantly reinforced (Hofstede, 2001). On the other hand, feminine cultural values are associated with greater equality of emotional and gender roles. Both, men and women are modest and caring, the balance of work and family is sought, and sympathy for the weak is expressed. In conflict management 
and negotiation studies, masculinity is expected to be connected with competitive styles, while on the opposite femininity seems to be connected with cooperative styles (Nelson, Bronstein, Shacham, \& BenAri, 2015). Thus:

Hypothesis 4a: Masculinity is positively related to a competitive style of negotiation. Hypothesis 4b: Masculinity is negatively related to a cooperative style of negotiation.

Long-term vs. Short-term Orientation. Long-term Orientation, as opposed to Short-term Orientation, describes how people maintains links with the past and deals with the present and the future. Individuals expressing long-term cultural values place a great emphasis on the future and expect that their most important lifetime events are yet to come. Therefore, they will more easily adapt their traditions and ethical values to situational changes. To achieve their future goals, they are more perseverant and show a tendency toward thrift and hard work. Contrary, individuals with short-term oriented cultural values uphold their traditions and are skeptical towards social changes (Hofstede, 2001). Now turning to the context of negotiations, we argue that individuals of long-term oriented cultures will prefer styles that are prone to cooperation. This is because, as long-term oriented cultures tend to prefer long-term gain, negotiators belonging to such cultural values will tend to value the relationship more than the outcome and, hence, will cooperate with the other party whenever possible. Conversely, as short-term oriented cultures prefer shortterm gain, we expect that individuals from such cultures will have a greater preference for competition in negotiations, as they may perceive higher immediate gains (Lewicki et al., 2014). Thus:

Hypothesis 5a: Long-term Orientation is negatively related to a competitive style of negotiation. Hypothesis 5b: Long-term Orientation is positively related to a cooperative style of negotiation.

\subsection{Negotiation Styles and Cultural Intelligence}

There is evidence that successful interactions between members of different cultures requires cultural intelligence (CQ). Following Groves \& Feyerherm (2011), the concept of CQ gained increasing attention because other existing theories of capabilities, e.g., cognitive, emotional, or social intelligence, do not offer a complete explanation in cross-cultural situations where people interact with others that adhere to different societal values and norms. In this vein, Caputo et al. (2018) have shown that cultural intelligence moderates the relationship between cultural orientations and conflict management styles. Even though concepts such as cognitive and emotional intelligence help the individual to understand various information this does not imply that such information will automatically be helpful in social interactions, especially in cross-cultural interactions. Having a high level of interpersonal skills in one's own culture does not necessarily mean that one can easily adapt to other people with a different cultural background.

The concept of cultural intelligence has already proven to be an important factor for management and organization studies (Triandis, 2006). To date, CQ has been studied across various domains, including team work (Adair et al., 2013), decision-making (Ang et al., 2007), leadership (Groves \& Feyerherm, 2011), knowledge management (Vlajčić, Caputo, Marzi, \& Dabić, 2018), and conflict management (Caputo et al., 
2018). It is somewhat surprising that scholars researching negotiation have not given much attention to this concept (Imai \& Gelfand, 2010). In this regard, Aycan and Gelfand (2012) encouraged scholars to explore the link between CQ and negotiation and to endorse the suggestions that the negotiator's cognitive ability increases the chance of win-win results in negotiations (Barry \& Friedman, 1998).

As described by Earley and Ang (2003), CQ is a multifaceted construct consisting of four elements: (i) metacognitive $C Q$, (ii) cognitive $C Q$, (iii) motivational CQ, and (iv) behavioral CQ. First, metacognitive CQ describes an individual's conscious awareness of the cultural interactions and, within such situations, the ability to identify own and other people's thoughts and to strategize. Second, cognitive CQ reflects an individual's knowledge of a cultural group's values, beliefs, and norms and is the degree of understanding their importance and impact on social interactions across cultures, especially in situations of doing business. The third element, motivational CQ, reflects an individual's interest, drive, directed energy, and willingness to learn about cultural differences. It therefore very much involves intrinsic motivation, i.e., the personal enjoyment derived from culturally diverse situations, extrinsic motivation, i.e. the tangible benefits of culturally diverse experiences, and self-efficacy, i.e., the confidence that one can act effectively and be successful in cross-cultural encounters. Finally, behavioral CQ is an individual's ability to choose the appropriate verbal and physical actions and thereby, to effectively accomplish her goals when interacting with people from different cultures.

Given the above, difficult interactions such as negotiations can threaten the productivity and other outcomes in culturally diverse settings (e.g., Mannix \& Neale, 2005). We propose that CQ may mitigate such difficulties especially when values and beliefs differ (e.g., Brett, 2007; Jehn, 1995; Lewicki et al., 2014). In a multi-cultural situation, an individual with high CQ is able to better understand cultural differences and, thereupon, to adapt the behavior to "fit in" with these different values, norms, and beliefs. Thereby, this person is more likely to be accepted by the others and, consequently, will feel more accepted. Such mutual dynamics can foster the comfort of everyone in these work-setting and eases the boundaries of potential differences and conflicts. For example, we propose that a culturally intelligent negotiator may easily adapt to the local customs and understand how Japanese negotiators may prefer to share information directly, whereas French negotiators prefer a more direct style of communication. Similarly, the same culturally intelligent negotiator may understand the dynamics of a foreign culture and deploy appropriate tactics in terms of sweet-talk and logrolling.

Very few studies have related CQ with negotiation styles. In a recent empirical study, Imai and Gelfand (2010) found that individuals with higher CQ have a greater motivation to cooperate compared to those with lower CQ. They also discovered that in two-party negotiations between individuals with higher behavioral and metacognitive CQ the individuals engage more often in effective sequences of integrativeinformation behaviors than do negotiators with lower CQ. Thus, we expect that negotiators who are more cooperative and possess a higher CQ are more likely to adopt negotiation strategies that are more integrative. 
With a cross-cultural negotiation experiment, Groves et al. (2015) delivered first evidence supporting our assumption. They showed that CQ predicted negotiation performance and, in particular, that high levels of CQ were positively related to cooperative negotiation styles.

Evidence from prior research on negotiation posited that each style has some attributes inferred from the individual and her attributes and characteristics (e.g., Elfenbein, 2015; Sharma et al., 2013). Such individual traits and attitudes are also affected by the cultural differences and cultural values of the involved parties, which, in turn, can affect their understanding of the negotiation situation. Thus, we argue that CQ, as a second order four-dimensional construct, mediates the relation between each of the cultural values and both of the negotiation styles. Indeed, we propose that CQ will mitigate the impact of differing cultural values, since individuals with higher CQ can more easily adapt their behavior to fit in to the different culture. Thus:

Hypothesis 6a: Cultural intelligence will mediate the relationships between each cultural values and competitive negotiation style.

Hypothesis 6b: Cultural intelligence will mediate the relationships between each cultural value and cooperative negotiation style.

- - - Please Insert Figure 1 about here - - -

\section{Method}

\subsection{Procedure and sample}

Data were collected through an online survey, distributed in February and September 2016, using a crowdsourcing platform (www.prolific.ac), which allows the compensation of participants for their time, and through random selection from a pool of currently employed non-student individuals via the researchers personal network on LinkedIn. A total of 431 completed questionnaires were received, of which 28 had to be eliminated because they failed the instrumental manipulation check, which consisted of "non-sensical" tasks included to ensure participants were paying attention (Berinsky, Margolis, \& Sances, 2014). The final set comprised 403 questionnaires. This resulted in a sample of diverse and experienced employees, working in various organizations, avoiding single-source bias. The demographic profile of the sample is provided in Table 1.

\section{- - - Please Insert Table 1 about here - - -}

In quantitative research, it is common to use self-administered surveys to investigate the nature of cultural practices such as cultural intelligence and negotiations styles. However, the problem with such surveys is that respondents often tend to give (consciously or not) directional responses (Paulhus, 1991; Warner, 1965). We carried out a series of robustness checks to assure that this bias does not jeopardize the validity of our data (Podsakoff, MacKenzie, Lee, \& Podsakoff, 2003). To do so, we, first, conducted a $t$ - 
test and compared the responses of early and late respondents, not finding any statistically significant differences between groups. We checked for common method variance using the Harman one-factor method (Gunkel et al., 2016; Podsakoff et al., 2003) which showed that the first factor accounted for only $11 \%$ of the total variance, suggesting no serious common method bias.

\subsection{Measures}

Negotiation Styles. Respondents' negotiation styles were obtained with the 16-Item scale provided by Livingston (2014), which is a retrospective measure of how individuals apply negotiation styles. This scale assesses, using a 5-point Likert scales, the cooperative and competitive negotiation style with eight items each.

Cultural Values. We collected primary data on cultural values at the individual level for several reasons. First, with own data collected on cultural values we did not have to rely on the national culture scores provided by Hofstede (1980), which has been often criticized for its organizational sample bias. Another advantage of collecting such own data is that cultural values are not assigned to individuals solely because of their geographical residence. And finally, our cultural value data is enriched with within country variation. To measure cultural values, we used the CVSCALE (Yoo et al., 2011), which is 26-item instrument that measures, on 5-point Likert scale, Hofstede's five cultural dimensions at the individual level.

Cultural Intelligence. Cultural intelligence is a second-order construct, which was assessed with four first-order dimensions using the Cultural Intelligence Scale (CQS) (Ang et al., 2007). Altogether, these four first-order factors, i.e., cognitive, metacognitive, motivational, and behavioral intelligence, were measured with a total of 20 items, on a 5-point Likert scale.

All items used in the above scales as well as their descriptive statistics are provided in the appendix.

For all constructs, we computed scale scores by using the average of their composite items on the 5-point Likert scale (see Table 2). For analyzing the individual constructs, we used all items of each scale. However, some items of the Long-term Orientation construct had to be dropped to achieve good model fit for Cultural Orientation $(\mathrm{CV})$. As required, the revised measurement model provided at least three items for a latent construct (see e.g., Gunkel et al., 2016, p. 576).

\section{Analysis and results}

\subsection{Measurement model validation}

The first step of our analysis was to determine the reliability and validity of the measurement through the AMOS v24 package in SPSS. Following Hair et al. (2016), we, first, assessed the internal consistency using Cronbach's Alpha and the Composite Reliability (CR). Generally, Cronbach's alphas exceeding 0.70 are considered acceptable and CR values above 0.70 are satisfactory (Nunnally \& Bernstein, 1994). As shown in Table 2, our first-order constructs meet these criteria and are, thus, reliable. We further checked for validity with the Average Variance Extracted (AVE), which should exceed 0.50 for convergent 
validity (Fornell \& Larcker, 1981). Some of our constructs did not meet this criterion. However, there are researchers who argue that this criterion related to the AVE is too restrictive and, instead, the AVE should exceed the shared variance (Farrell, 2010; Voorhees, Brady, Calantone, \& Ramirez, 2016). As outlined in Table 2 and Table 4, our constructs met these criteria (see also, Andrews \& Bianchi, 2013; Vander Elst, Van den Broeck, De Cuyper, \& De Witte, 2014).

- - - Please Insert Table 2 about here - - -

To further assure construct validity of our multi-dimensional constructs, we also conducted Confirmatory Factor Analyses (CFA) using maximum likelihood estimation. There is no general consensus in the literature on structural equation models (SEM) on which measures to use to assess model fit for CFAs (Hooper, Coughlan, \& Mullen, 2008). For example, some recommend use of at least three fit tests (Jaccard, Wan, \& Jaccard, 1996); while others recommend at least four tests (Kline, 2015), the $\chi^{2}$, the Comparative Fit Index (CFI), Root-Mean-Square Error of Approximation (RMSEA), and Standardized Root-MeanSquare Residual (SRMR). Hu and Bentler (1999) suggest a two-index presentation format, which should include the SRMR with the NNFI (TLI), RMSEA or the CFI. Reviewing these recommendations, we followed Kline (2015) who advocates the use of the Chi-Square test, the CFI, the RMSEA, and the SRMR. Chi-Square values between 0 and 3 are considered as acceptable (Marsh \& Hocevar, 1985; McIver \& Carmines, 1981; Pappas, 2018), whereas the CFI should be 0.90 and above (Hu and Bentler, 1999). A RMSEA of less than 0.05 indicates good and less than 0.08 acceptable fit (Schermelleh-Engel, Moosbrugger, \& Müller, 2003), which also holds for the SRMR (Hu \& Bentler, 1999).

As Table 3 shows, all our multi-dimensional constructs meet the at least acceptable requirements.

- - - Please Insert Table 3 about here - - -

In order to check for multicollinearity issues among our variables, we followed Hair et al. (2016)

and examined whether there are bivariate correlations above 0.90 or several bivariate correlations above 0.70. (Hair et al. 2016). The highest correlation among our variables is 0.616 as can be seen in the correlation matrix in Table 4. Thus, we conclude that there are no multicollinearity problems.

- - - Please Insert Table 4 about here - - -

\subsection{Structural model and hypotheses testing}

As can be seen in Figure 1, our theoretical model comprises two dependent variables (i.e., 
cooperative negotiation style and competitive negotiation style), five independent variables (i.e., the five cultural values - power distance, uncertainty avoidance, collectivism, masculinity, and long term orientation), and one a second order four-dimensional construct as a mediation variable (i.e., cultural intelligence, composed of metacognitive CQ, cognitive CQ, motivational CQ, and behavioral CQ).

- - - Please Insert Figure 2 about here - - -

With reference to our conceptual and hypothesis testing model in Figure 2, by using the Hayes (2018, p. 6) simple mediation and also as illustrated by Preacher et al. (2007, p. 188), we deduced and set up our mediation process using the following equations:

$$
\begin{aligned}
C Q & =a_{o}+a_{m}(C V)+\varepsilon_{1} \\
\text { and } \quad N S & =\beta_{0}+\beta_{m}(C V)+b_{m}(C Q)+\varepsilon_{2}
\end{aligned}
$$

where $a_{o}$ and $\beta_{0}$ are the constant terms; $\beta_{m}$ and $a_{m}$ are the coefficients of the CVs (with $m$ taking the values of $1-5$ for the respective CVs, PO; UN; CO; LTO; MA); $b_{m}$ is the coefficient for the relationship between $\mathrm{CQ}$ and NS; and $\varepsilon_{1}$ and $\varepsilon_{2}$ are the residuals for estimating the two equations. For simplicity in all subsequent equations, the residual terms are not denoted (see Hayes, 2018, p. 6).

Combining equations (1) and (2):

$$
\begin{array}{cl} 
& N S=\beta_{0}+\beta_{m}(C V)+b_{m}\left[a_{o}+a_{m}(C V)\right] \\
& =\beta_{0}+\beta_{m}(C V)+b_{m} a_{o}+b_{m} a_{m}(C V) \\
\text { and rearranging } & N S=\left[\beta_{0}+b_{m} a_{o}\right]+\beta_{m}(C V)+b_{m} a_{m}(C V)
\end{array}
$$

equation (3), $\left[\beta_{0}+b_{m} a_{o}\right]$ now represents the constant terms. For the testing and conclusion reached about our hypotheses, the $\beta_{m}$ are thus the direct coefficients and if significant then we will conclude that our hypotheses about the direct effects are supported.

To test for the mediation, there are many methods and approaches suggested in the literature (Kenny, 2008; Preacher \& Hayes, 2004), and the two most popular methods used to detect mediation are the Sobel test (Sobel, 1982) and the causal approach by Baron and Kenny (1986). Both approaches are not without their problems - the Sobel test has often been criticized for its requirements that the sampling distribution of the indirect effect should be normal (a requirement that is not easily met), while the Baron and Kenny (1986) causal approach is also criticised for its low statistical power (Fritz \& MacKinnon, 2007; Hayes, 2009). To overcome these shortcomings, the literature recommends the use of bootstrapping (Bollen \& Stine, 1992; Cheung \& Lau, 2008; Hayes, 2009; Lockwood \& MacKinnon, 1998). We are also justified to use bootstrapping since our sample is large enough $(n=403)$ and thus we reduced the risk of committing type 1 error, which is a criticism of this technique (see Koopman, Howe, Hollenbeck, \& Sin, 2015).

In our equation (3), we can now represent the coefficients $b_{m} a_{m}$ with $\gamma_{m}$. Then $\gamma_{m}$ now represents the indirect coefficients of the respective CVs and if they are significant, then we can establish that there is 
a full mediation of the CVs to NS relationships by CQ, supporting our mediation hypotheses. If for any CV both $\beta_{m}$ and $\gamma_{m}$ are significant, then we will conclude that there is only partial mediation.

We can now put the two negotiation styles (NS) and also the five Cultural Values (CVs) in equation (3), and again for simplicity the constant is not denoted in the final two equations below (see Hayes, 2018, p. 6). In all our results we reported the standardized coefficients.

For the competitive negotiation style, using $\alpha$ to represents the betas $\beta_{m}$, we have:

$$
\begin{aligned}
C O M P & =\alpha_{1}(P O)+\gamma_{1}(P O)+\alpha_{2}(U N)+\gamma_{2}(U N)+\alpha_{3}(C O)+\gamma_{3}(C O)+\alpha_{4}(L T O)+\gamma_{4}(L T O) \\
& +\alpha_{5}(M A)+\gamma_{5}(M A)
\end{aligned}
$$

For the cooperative negotiation style, using $\lambda$ to represents the betas $\beta_{m}$, we have:

$$
\begin{aligned}
C O O P & =\lambda_{1}(P O)+\gamma_{1}(P O)+\lambda_{2}(U N)+\gamma_{2}(U N)+\lambda_{3}(C O)+\gamma_{3}(C O)+\lambda_{4}(L T O)+\gamma_{4}(L T O) \\
+ & \lambda_{5}(M A)+\gamma_{5}(M A)
\end{aligned}
$$

We therefore undertook our mediation test using the AMOS software, and using 5,000 bootstrap samples, maximum likelihood estimators, a bootfactor of 1 , and 90 percent bias-corrected confidence intervals. Overall, this structural mediation model explains the data well $\left(X^{2}=2937.50, d f=1613, X^{2} / d f=\right.$ $1.821, p=0.000, \mathrm{CFI}=0.87, \mathrm{RMSEA}=0.045, \mathrm{SRMR}=0.067)$. The five cultural values explain medium levels of variance in our mediator cultural intelligence $\left(R^{2}=0.14\right)$, but altogether they all explain relatively high variance (Cohen, 1992) in both the competitive negotiation style $\left(R^{2}=0.51\right)$ and the cooperative negotiation style $\left(R^{2}=0.41\right)$.

Our results indicated that direct relationship between CQ and each of the negotiation styles (Competitive and Cooperative) is significant (supporting Groves et al., 2015). The standardized coefficient respectively are $0.184, p<0.01$ and $0.243, p<0.001$. Also, the significance of the $p$-values are two-tail indicating that the relationships is both directions. The standardized direct and indirect effects of each cultural value on both negotiation styles with the mediator included are given in Figure 3 and Table 5.

- - - Please Insert Figure 3 about here - - -

- - - Please Insert Table 5 about here - - -

With respect to our hypotheses, we see that power distance has a significant positive relationship with competitive negotiation style $\left(\alpha_{1}=0.210 ; p<0.05\right)$ but a non-significant relationship with cooperative negotiation style $\left(\lambda_{1}=-0.013 ; p=\right.$ n.s. $)$, thus, confirming H1a but not H1b. Our results further revealed that 
the relationship between uncertainty avoidance and the competitive negotiation style is non-significant $\left(\alpha_{2}\right.$ $=0.097 ; p=$ n.s.). However, as we hypothesized, its relationship with the cooperative negotiation style is positive and highly significant $\left(\lambda_{2}=0.345 ; p=0.001\right)$. Thus, $\mathrm{H} 2 \mathrm{a}$ is not supported whereas $\mathrm{H} 2 \mathrm{~b}$ is supported. As can further be seen in Figure 3 and Table 5, collectivism has no relationship with competitive negotiation style $\left(\alpha_{3}=-0.114 ; p=\right.$ n.s. $)$ but as we posited, there was a significant relationship with cooperative negotiation style $\left(\lambda_{3}=0.148 ; p=0.05\right)$. Therefore, H3a is not supported but H3b is supported. Our results also supports our hypothesized relationships of masculinity with the two negotiation styles. Masculinity was positively and significantly highly related to competitive $\left(\alpha_{4}=0.524 ; p<0.001\right)$; and also negatively and significantly highly related to cooperative $\left(\lambda_{4}=-0.271 ; p=0.001\right)$, lending support to both H4a and H4b. Contrary to our hypotheses, the results did not reveal any significant relationship between long-term orientation and the competitive negotiation style $\left(\alpha_{5}=0.074 ; p=\right.$ n.s. $)$ nor the cooperative negotiation style $\left(\lambda_{5}=0.129 ; p=\right.$ n.s.). Therefore, there is no support for both H5a and H5b.

To sum up, for the direct relationships of the Cultural Values with the Negotiation Styles, the competitive negotiation style was mostly influenced by masculinity $\left(\alpha_{4}=0.524\right)$ followed by power distance $\left(\alpha_{1}=0.210\right)$ and the cooperative negotiation style was most influenced by uncertainty avoidance $\left(\lambda_{2}=0.345\right)$, followed by the negative influence of masculinity $\left(\lambda_{4}=-0.271\right)$ and the positive impact of collectivism $\left(\lambda_{3}=0.148\right)$.

Finally, we hypothesized in H6a and H6b that the second order construct of cultural intelligence CQ will mediate the relation between each of the five cultural values and the two negotiation styles. As summarized in Figure 3 and Table 5, the results of our bootstrapping mediation analysis revealed the following. For the H6a, we had support for two of the five possible mediations. These were for the collectivism to competitive negotiation style relationship, there was no significant direct effect $\left(\alpha_{3}=-0.114\right.$; $p=$ n.s.) but there was a significant indirect effect $\left(\gamma_{3}=0.033 ; p<0.05\right)$, and so based our mediation testing approach (see section 4.2) this represents a full mediation. Again for the long-term orientation to competitive negotiation style relationship there was no significant direct effect $\left(\alpha_{5}=0.074 ; p=\mathrm{n} . \mathrm{s}\right.$.), but there was a significant indirect effect $\left(\gamma_{5}=0.036 ; p<0.05\right)$, and this also represents a full mediation. This shows that for H6a, two of the possible five mediations are supported.

For the H6b, we had support for only one of the five possible mediations, and this mediation was actually only a partial mediation. This was for collectivism to cooperative negotiation style relationship, there was a significant direct effect $\left(\lambda_{3}=0.148 ; p<0.05\right)$ and at the same time there was a significant indirect effect $\left(\gamma_{3}=0.044 ; p<0.05\right)$, and so based our mediation testing approach this represents a partial mediation. This shows that for H6b, only one partial mediation support out of the possible five.

\section{Discussion}

The current study contributes to the existing knowledge on determinants of negotiation styles by 
examining, first, the direct effects of cultural values and cultural intelligence on negotiation styles and, second, by testing whether cultural intelligence also mediates the effect of cultural values on negotiation styles. Our findings indicate that cultural values affect the choice of negotiation styles, either directly or through the mediation of cultural intelligence. Moreover, we also found that cultural intelligence has a direct impact on both negotiation styles.

\section{Direct effects of cultural values on competitive negotiation style.}

Our model revealed that individuals with higher levels of power distance and masculinity tend to use a competitive negotiation style (H1a, H4a), which is in line with previous findings. For example, Graf et al. (2012) found that negotiators from power distant cultures (e.g. Asian) tend to apply more powerrelated strategies. We found that an increase in power distance is linked with an increase in using a competitive negotiation style. This means that individuals who accept the unequal distribution of power (i.e., who score high in power distance) may consider it normal that negotiations end with winners and losers. This suggests that rather than searching for common goals, they might accentuate their own gains, want to come off as winners, and, therefore, are more willing to compete.

Moreover, our results reinforced findings by Amanatullah and Morris (2010) who found that even self-advocating female negotiators conceded away only roughly $20 \%$ of the total value in just the first round of negotiation, indicating a cooperative negotiation style. Contrary, this implies that individuals with high values of masculinity tend to use competitive negotiation styles.

Contrary to our hypotheses (H2a, H3a, H5a), we did not find any evidence that the competitive negotiation style is impacted by uncertainty avoidance, collectivism, and long term orientation. This is surprising. We expected that individuals with long term orientation would be more motivated to cooperative negotiation styles because they would prefer maintaining good relationships for their long term gains. Within the context of conflict management, Caputo et al. (2018) found that long-term orientation was positively related to problem solving. Taken together, this perhaps indicates that individuals with long-term orientation are more calculative about their gains and are, therefore, more competitive to ensure their realization.

\section{Direct effects of cultural values on cooperative negotiation style.}

Our data revealed that individuals who reported higher levels of uncertainty avoidance and collectivism and lower levels of masculinity also reported higher levels of cooperative negotiation style (H2b, H3b, H4b). In particular, we found that an increase in uncertainty avoidance is linked with an increase to use a cooperative negotiation style. Our findings may be explained by the work of Graham et al. (1988) who showed that individuals with higher uncertainty avoidance tend to experience more stress and anxiety and, thus, need more clarity and structure. They also suggest that such individuals must trust, share information, and communicate more openly with their negotiation partners to reduce the risk in their relationship. Hence, it is possible that individuals with higher uncertainty avoidance are inclined towards 
cooperative negotiations as in such there might be more open communication with the other party which provides reliably information and reduces risk and stress

Additionally, our findings suggest that individuals high in collectivism are also linked with cooperative negotiation style. This is a new and important finding. Prior findings in this area are rather contradictory possibly because collectivism has mainly been operationalized at the national level. In this study, we operationalized cultural values (e.g. collectivism) at the individual level allowing us to capture an individual's negotiation style regardless of the nationality cultural values. Given the fact that collectivistic individuals think "we" and behave in favor of their group, this orientation is crucial in fostering integrative, i.e., cooperative negotiations (Cai et al., 2000; Caputo, 2016; Traavik, 2011).

Moreover, we found that lower levels of masculinity relate to cooperative negotiation styles. This finding is aligned with studies on conflict management (e.g., Caputo et al., 2018; Gabrielidis, Stephan, Ybarra, Pearson, \& Villareal, 1997) suggest that low levels of masculinity are related to problem solving.

The mediation effects of $C Q$ on the relationship between cultural values and competitive and cooperative negotiation styles.

Our mediation analysis revealed that CQ mediates three effects. First, the direct relation between collectivism and the competitive negotiation style is completely absorbed by CQ. This suggests that individuals with higher levels of collectivism will only chose a competitive negotiation style if they also score high on CQ. As a consequence, this finding implies that CQ is more decisive for choosing a competitive style than the negotiator's collectivistic values. Second, CQ partially mediates the effect of collectivism on the cooperative negotiation style to a small degree. This finding confirms the fact that collectivists are already inclined to looking for their peers, are sensitive to other people's needs, enjoy harmonious interactions (Traavik, 2011) and are already tend to be cooperative. In this respect, CQ only slightly affects these people's general tendency to engage in a cooperative negotiation style. And third, we also found that CQ fully absorbs the effect of long term orientation and the choice of a competitive negotiation style. This result explains findings of earlier studies that show that long-term orientation is positively related to problem solving but also to emotional intelligence (see Gunkel et al., 2016).

Altogether, the results of our mediation analysis highlight the special role of CQ. Apparently, individuals with high CQ (i.e. conscious awareness and sensitivity in cultural interactions, the ability to strategize when crossing cultures, a knowledge of a group's values, beliefs, and norms, and the understanding of culture in cross cultural business interactions, the willingness and motivation to learn about cultural differences, and the ability to choose appropriate verbal and physical actions when interacting with people of different cultures) are more flexible in choosing their negotiation style when dealing with people from other cultures.

CQ did not mediate the link between power distance, uncertainty avoidance, masculinity, long term orientation and the cooperative negotiation styles. There may be several reasons for this lack of mediation. 
First, the composition of our participants may have distorted the pattern of our results. For example, the majority of our participants is male and Caucasians. Prior research shows that men's behaviors on average are more competitive than women's caring behaviors (Walters, Stuhlmacher, \& Meyer, 1998), that men are more strongly connected with power, status (Ridgeway, 2001), and assertiveness, meaning they are highly protective of their own interests (Williams \& Best, 1982). Also, given that negotiation is a task in which masculine stereotypes enjoy a positive association, gender stereotypes are activated during the negotiation (Miles \& Clenney, 2010). Our results suggest that these male gender stereotypes are strongly and directly connected with competitive negotiation style regardless of CQ. Hence, our predominantly male sample may explain this pattern of results.

Second, since the beginning of studies on CQ (see Earley \& Ang, 2003), there have been repeated calls to use CQ as a composite variable (i.e. second order factor) rather than aggregating its four aggregate factors (Ang et al., 2007). Our study has answered these calls and measures CQ as a composite variable. However, there is a possibility that our insignificant findings for CQ as a mediator for the relationship between the majority of the cultural values (i.e. power distance, uncertainty avoidance, masculinity and long term orientation) may be related to the original CQ scales, which were not explicitly developed for a composite construct. Thus, new scales for measuring CQ as a composite variable might shed light on more mediation effects.

\section{Theoretical and Practical Implications}

Our study has interesting theoretical as well as practical implications. Negotiation is among the key activities performed in a workplace to which employees and managers bring in their own cultural values and differences. Thus, it is imperative that managers understand their implications. We have, first, theoretically extended the literature on culture and negotiation. By today, existing literature has largely focused on the impact of cultural differences on negotiation processes and outcomes (e.g., Adair \& Brett, 2005; Gelfand et al., 2013; Gelfand \& Christakopoulou, 1999; Vieregge \& Quick, 2011). The major shortcoming of these studies is that they have analyzed these relations by utilizing cultural values at a national level. However, negotiations happen between people, thus, these processes must be examined at the individual level. In particular, Vieregge and Quick (2011) argue that previous research failed to provide a systematic approach to the relationship between cultural values and certain negotiation styles. Our study bridges this gap and examines the relation between individual cultural values and two different negotiation styles. Our results showed that individuals scoring high on power distance, collectivism, and masculinity are more likely to favor a competitive negotiation style and those people with high uncertainty avoidance, collectivism, and masculinity values tend to prefer a cooperative negotiation style.

Moreover, our study sheds more light on the role of CQ for a person's preference of either negotiation style. Our major contribution here is that we are among the first who considered CQ as 
mediating variable (Ott \& Michailova, 2018) instead of a moderating variable as numerous previous studies did. In particular, we are the first who studied CQ as a mediator in the relation between cultural values and negotiation styles. We find that CQ mediates the relationship between two cultural values (collectivism, long term orientation) and the competitive as well as the cooperative negotiation styles.

Likewise, most existing studies use CQ as a first order construct and measure and treat its dimensions separately (Kim \& Van Dyne, 2012; Koo Moon, Kwon Choi, \& Shik Jung, 2012; Remhof, Gunkel, \& Schlaegel, 2014). With this current study, we departed from this usual approach and used the CQ scales to compose CQ as a second order construct and thereby answer calls for such studies (Bücker, Furrer, \& Peeters Weem, 2016). Despite a few interesting results, this approach may have also been responsible for our non-findings. Nonetheless, future research might confirm the value in treating CQ as a composite second-order variable.

In terms of practical implications, our results suggest that managers need to understand the importance of not just negotiating across cultures but the role of CQ in this endeavour. We now know that individual cultural values are critical for cross-cultural negotiation while CQ is an important mediator especially in the relationship between collectivism, long term orientation and competitive negotiation style. Also, CQ is a mediator of the relationship between collectivism and cooperative negotiations style.

Finally and given our results, training is implicated. Managers and negotiators who would like to successfully traverse across cultures and within global environments will benefit from training in CQ. Specially, conflict and negotiation training packages should not only train negotiation skills but also CQ competencies to effectively negotiate. This implies that also organizations should train their employees in CQ so that there are fewer negotiation challenges caused by differences in cultural values.

\subsection{Limitations and future research}

Even though the results are interesting and, in parts, counterintuitive, this study has several limitations. First, we used self-reported measures, which may be vulnerable to common method bias - a phenomenon that is often present when single-source, self-reported data is used. Despite our carefully selected measure to eliminate this bias, our data might still be subject to it. However, the high quality and representativeness of our sample should reduce this bias. Unlike most negotiation-studies with student samples, our respondents are experienced employees from a diverse set of organizations. Thereby, we reduce the risk of the single-source bias. In contrast to experiments which happen in laboratories, we collected data through an online survey, thus, there was no possibility to control for possible influences of the environment. Even though our statistics reported good or at least satisfactory results, we encourage scholars to gather data on this subject in different was, e.g., case studies, online or laboratory experiments. Third, we treated CQ as a second-order construct composed of its four facets. We have used existing scales to measure these facets, which may have caused the few non-findings of our study. To shed more light on 
the role of CQ as a mediator in the relation between cultural values and negotiation styles as well as other hypothesized relations, we encourage researchers to develop and test new scales for this purpose. Finally, even though our sample represents only a small specific part of the general population of a multicultural organizational environment, we believe it still makes important contributions of exploratory nature.

Our study offers some implications for researchers to deepen our understanding of the role of cultural intelligence in negotiation and to examine some of the issues not addressed in this study. First, using different samples to replicate this study is a reasonable expansion for this line of research. Second, using different methodologies, e.g., experiments and qualitative methods, might reveal further interesting relations. We believe it would be particularly interesting to investigate the impact of cultural intelligence in real life negotiations, and its role in, e.g., determining first offers. In this vein, longitudinal studies could also provide an important avenue for researchers, allowing to observe the behaviour of negotiators over time and gathering both qualitative and quantitative data to understand how and why negotiations happen the way they do. A last interesting avenue for future studies would be to investigate the role of cultural intelligence in possibly mitigating cognitive biases in negotiation.

\section{Conclusion}

To the best of our knowledge this study is the first that explicitly investigates the relationship between cultural values, cultural intelligence, and negotiation styles at the individual level; and its contribution is unique in investigating the interplaying dynamics among those variables. Most of the research in negotiation adopts a comparative approach in describing and explaining cultural differences among different samples, where culture is usually indirectly measured as nationality or ethnicity. We believe this approach, which has helped research in understanding many aspects of cross-cultural relations, is close to have exhausted its ability to advance research. A more complex and globalized world calls for more complex and integrated research approaches, contributing more toward the integration of different cultures, rather than their comparison. We believe by measuring directly cultural intelligence and cultural values, research in negotiation can contribute to the understanding of important and complex dynamics of today's environments.

\section{Acknowledgments}

The authors would like to thank the Associate Editor Dr Jane Maley and the anonymous reviewers for their insightful comments on the manuscript.

\section{Authors Biographies}

Andrea Caputo is Reader in Strategy \& Entrepreneurship at the Lincoln International Business School (UK) and member of the UNESCO Chair on Responsible Foresight for Sustainable Development. He received his PhD in Management from the University of Rome Tor Vergata. He has also been a Visiting scholar at the University of Queensland Business School, at The George Washington School of Business, the University of Sevilla, the University of Alicante, and at the University of Pisa. His main research 
interests are related to entrepreneurship, negotiation, decision-making, and strategic management. He published more than 40 papers in several international journals, including JBR, BPMJ, EBR, IJEBR and IJCMA among others.

Oluremi B. Ayoko is Associate Professor of Management in the UQ Business School at the University of Queensland, Australia. Remi's principal research interests include conflict management, emotions, leadership, diversity, team work and employee physical work environment and territoriality. The results of her cutting-edge research have been presented in several international and national conferences. Remi is an award-winning researcher and has published in journals such as JOB, APIR, IJCMA, and SGR. She has also written many book chapters and co-edited a Handbook of Conflict Management Research (Edward Edgar Publishers). Remi is an Associate Editor of the Journal of Management and Organization.

Nii Amoo is Senior Lecturer at Leeds Beckett University. He received his $\mathrm{PhD}$ in Management from the Leeds University Business School. His research interest are in strategy and leadership with emphasis on implementation, SMEs and Family Businesses. His research work has been presented in a number of international conferences including the BAM and the AOM. Nii's work has been published in a number of international journals, including the Journal of Management Inquiry (JMI), Journal of Business Research (JBR), Energy Economics (EE), International Journal of Sustainable Strategic Management (IJSSM), and Management Control. He is also an Article Editor for Sage Publications.

Charlott Menke is a PhD Student at Otto-von-Guericke University in Germany. Her research focuses on negotiation as well as individual-level and country-level determinants of different forms of entrepreneurial activity. Her particular interests include decision-making processes, personality, utility, and cultural values affecting commercial and social entrepreneurship and her work has been presented at a number of international conferences such as the European Academy of Management, the Academy of Management, the Annual Social Entrepreneurship Conference, and the Australian Conference for Entrepreneurship Research Exchange. Moreover, Charlott published in the International Journal of Entrepreneurial Venturing (IJEV).

\section{References}

Adair, W. L., \& Brett, J. M. (2005). The Negotiation Dance: Time, Culture, and Behavioral Sequences in Negotiation. Organization Science, 16(1), 33-51.

Adair, W. L., Hideg, I., \& Spence, J. R. (2013). The Culturally Intelligent Team The Impact of Team Cultural Intelligence and Cultural Heterogeneity on Team Shared Values. Journal of Cross-Cultural Psychology, 44(6), 941-962.

Andrews, L., \& Bianchi, C. (2013). Consumer internet purchasing behavior in Chile. Journal of Business Research, 66(10), 1791-1799.

Ang, S., Van Dyne, L., Koh, C., ng, K. Y., Templer, K. J., Tay, C., \& Chandrasekar, N. A. (2007). Cultural Intelligence: Its Measurement and Effects on Cultural Judgment and Decision Making, Cultural Adaptation and Task Performance. Management and Organization Review, 3(3), 335-371. https://doi.org/10.1111/j.1740-8784.2007.00082.x

Baron, R. M., \& Kenny, D. A. (1986). The moderator-mediator variable distinction in social psychological research: conceptual, strategic, and statistical considerations. Journal of Personality and Social Psychology, 51(6), 1173-1182.

Barry, B., \& Friedman, R. A. (1998). Bargainer characteristics in distributive and integrative negotiation. Journal of Personality and Social Psychology, 74(2), 345-359. https://doi.org/10.1037/0022- 
3514.74.2.345

Berinsky, A. J., Margolis, M. F., \& Sances, M. W. (2014). Separating the Shirkers from the Workers? Making Sure Respondents Pay Attention on Self-Administered Surveys. American Journal of Political Science, 58(3), 739-753.

Bollen, K. A., \& Stine, R. A. (1992). Bootstrapping goodness-of-fit measures in structural equation models. Sociological Methods \& Research, 21(2), 205-229.

Brett, J. M. (2007). Negotiating globally: How to negotiate deals, resolve disputes, and make decisions across cultural boundaries. San Francisco, CA: Jossey-Bass.

Brett, J. M., \& Okumura, T. (1998). Inter- and intracultural negotiation: U.S. and Japanese negotiators. Academy of Management Journal, 41(5), 495-510. https://doi.org/10.2307/256938

Bücker, J., Furrer, O., \& Peeters Weem, T. (2016). Robustness and cross-cultural equivalence of the Cultural Intelligence Scale (CQS). Journal of Global Mobility: The Home of Expatriate Management Research, 4(3), 300-325.

Cai, D. A., Wilson, S. R., \& Drake, L. E. (2000). Culture in the context of intercultural negotiation: Individualism-collectivism and paths to integrative agreements. Human Communication Research, 26(4), 591-617. https://doi.org/10.1111/j.1468-2958.2000.tb00770.x

Caputo, A. (2016). Overcoming judgmental biases in negotiations: A scenario-based survey analysis on third party direct intervention. Journal of Business Research, 69(10), 4304-4312. https://doi.org/http://dx.doi.org/10.1016/j.jbusres.2016.04.004

Caputo, A., Ayoko, O. B., \& Amoo, N. (2018). The moderating role of cultural intelligence in the relationship between cultural orientations and conflict management styles. Journal of Business Research, 89, 10-20. https://doi.org/10.1016/j.jbusres.2018.03.042

Cheung, G. W., \& Lau, R. S. (2008). Testing mediation and suppression effects of latent variables: Bootstrapping with structural equation models. Organizational Research Methods, 11(2), 296-325.

Cohen, J. (1992). A power primer. Psychological Bulletin, 112(1), 155.

De Dreu, C. K. W., \& Boles, T. L. (1998). Share and share alike or winner take all?: The influence of social value orientation upon choice and recall of negotiation heuristics. Organizational Behavior and Human Decision Processes, 76(3), 253-276.

Diamantopoulos, A., \& Siguaw, J. A. (2013). Introducing LISREL: A guide for the uninitiated. Sage.

Earley, P. C., \& Ang, S. (2003). Cultural intelligence: Individual interactions across cultures. Stanford, CA: Stanford University Press.

Elfenbein, H. A. (2015). Individual Differences in Negotiation A Nearly Abandoned Pursuit Revived. Current Directions in Psychological Science, 24(2), 131-136.

Farrell, A. M. (2010). Insufficient discriminant validity: A comment on Bove, Pervan, Beatty, and Shiu (2009). Journal of Business Research, 63(3), 324-327. 
Fornell, C., \& Larcker, D. F. (1981). Structural equation models with unobservable variables and measurement error: Algebra and statistics. Journal of Marketing Research, 382-388.

Fritz, M. S., \& MacKinnon, D. P. (2007). Required sample size to detect the mediated effect. Psychological Science, 18(3), 233-239.

Gabrielidis, C., Stephan, W. G., Ybarra, O., Pearson, V. M. D. S., \& Villareal, L. (1997). Preferred styles of conflict resolution Mexico and the United States. Journal of Cross-Cultural Psychology, 28(6), $661-677$.

Gelfand, M. J., Brett, J. M., Gunia, B. C., Imai, L., Huang, T.-J., \& Hsu, B.-F. (2013). Toward a cultureby-context perspective on negotiation: Negotiating teams in the United States and Taiwan. Journal of Applied Psychology, 98(3), 504.

Gelfand, M. J., \& Christakopoulou, S. (1999). Culture and negotiator cognition: Judgment accuracy and negotiation processes in individualistic and collectivistic cultures. Organizational Behavior and Human Decision Processes, 79(3), 248-269.

Graf, A., Koeszegi, S. T., \& Pesendorfer, E.-M. (2012). Cross-cultural negotiations and power distance: Strategies applied by Asian and European buyers and sellers in electronic negotiations. Nankai Business Review International, 3(3), 242-256. https://doi.org/10.1108/20408741211264567

Graham, J. L., Kim, D. K., Lin, C.-Y., \& Robinson, M. (1988). Buyer-seller negotiations around the Pacific Rim: Differences in fundamental exchange processes. Journal of Consumer Research, 15(1), 48-54.

Groves, K. S., \& Feyerherm, A. E. (2011). Leader cultural intelligence in context: Testing the moderating effects of team cultural diversity on leader and team performance. Group \& Organization Management, 36(5), 535-566. https://doi.org/10.1177/1059601111415664

Groves, K. S., Feyerherm, A., \& Gu, M. (2015). Examining cultural intelligence and cross-cultural negotiation effectiveness. Journal of Management Education, 39(2), 209-243.

Gunia, B. C., Brett, J. M., \& Gelfand, M. J. (2016). The science of culture and negotiation. Current Opinion in Psychology, 8, 78-83.

Gunkel, M., Schlaegel, C., \& Taras, V. (2016). Cultural values, emotional intelligence, and conflict handling styles: A global study. Journal of World Business, 51(4), 568-585.

Hair Jr, J. F., Hult, G. T. M., Ringle, C., \& Sarstedt, M. (2016). A primer on partial least squares structural equation modeling (PLS-SEM). Sage Publications.

Harinck, F., \& De Dreu, C. K. W. (2004). Negotiating interests or values and reaching integrative agreements: the importance of time pressure and temporary impasses. European Journal of Social Psychology, 34(5), 595-611.

Hayes, A. F. (2009). Beyond Baron and Kenny: Statistical mediation analysis in the new millennium. Communication Monographs, 76(4), 408-420.

Hayes, A. F. (2018). Partial, conditional, and moderated moderated mediation: Quantification, inference, 
and interpretation. Communication $\quad$ Monographs, $\quad$ 85(1), https://doi.org/10.1080/03637751.2017.1352100

Hofstede, G. (1980). Culture's Consequences: International Differences in Work-related Values. CrossCultural Research and Methodology series. https://doi.org/10.5465/AME.2004.12689661

Hofstede, G. (2001). Culture's consequences: Comparing values, behaviors, institutions and organizations across nations. Beverly Hills, CA: Sage.

Hofstede, G. (2011). Dimensionalizing cultures: The Hofstede model in context. Online Readings in Psychology and Culture, 2(1), 8.

Hooper, D., Coughlan, J., \& Mullen, M. (2008). Structural equation modelling: Guidelines for determining model fit. Electronic Journal of Business Research Methods, 6(1), 53-60.

House, R. J., Hanges, P. J., Javidan, M., Dorfman, P. W., \& Gupta, V. (2004). Culture, leadership, and organizations: The GLOBE study of 62 societies. Sage publications.

Hu, L., \& Bentler, P. M. (1999). Cutoff criteria for fit indexes in covariance structure analysis: Conventional criteria versus new alternatives. Structural Equation Modeling: A Multidisciplinary Journal, 6(1), 155.

Imai, L., \& Gelfand, M. J. (2010). The culturally intelligent negotiator: The impact of cultural intelligence (CQ) on negotiation sequences and outcomes. Organizational Behavior and Human Decision Processes, 112(2), 83-98. https://doi.org/10.1016/j.obhdp.2010.02.001

Jaccard, J., Wan, C. K., \& Jaccard, J. (1996). LISREL approaches to interaction effects in multiple regression. sage.

Jehn, K. A. (1995). A multimethod examination of the benefits and detriments of intragroup conflict. Administrative Science Quarterly, 40(2), 256-282.

Kenny, D. A. (2008). Reflections on mediation. Organizational Research Methods, 11(2), 353-358.

Kim, Y. J., \& Van Dyne, L. (2012). Cultural intelligence and international leadership potential: The importance of contact for members of the majority. Applied Psychology, 61(2), 272-294.

Kirkman, B. L., Lowe, K. B., \& Gibson, C. B. (2006). A quarter century of culture's consequences: A review of empirical research incorporating Hofstede's cultural values framework. Journal of International Business Studies, 37(3), 285-320.

Kline, R. B. (2015). Principles and practice of structural equation modeling. Guilford publications.

Kong, D. T., Dirks, K. T., \& Ferrin, D. L. (2014). Interpersonal trust within negotiations: Meta-analytic evidence, critical contingencies, and directions for future research. Academy of Management Journal, 57(5), 1235-1255.

Koo Moon, H., Kwon Choi, B., \& Shik Jung, J. (2012). Previous international experience, cross-cultural training, and expatriates' cross-cultural adjustment: Effects of cultural intelligence and goal orientation. Human Resource Development Quarterly, 23(3), 285-330. 
Koopman, J., Howe, M., Hollenbeck, J. R., \& Sin, H.-P. (2015). Small sample mediation testing: Misplaced confidence in bootstrapped confidence intervals. Journal of Applied Psychology, 100(1), 194.

Lax, D. A., \& Sebenius, J. K. (1986). The Manager as Negotiator: Bargaining for Cooperation and Competitive Gain. New York: Macmillan.

Lewicki, R. J., \& Robinson, R. J. (1998). Ethical and unethical bargaining tactics: An empirical study. Journal of Business Ethics, 17(6), 665-682.

Lewicki, R. J., Saunders, D., \& Barry, B. (2014). Negotiation (7th ed.). New York: McGraw Hill.

Liu, L. A., Chua, C. H., \& Stahl, G. K. (2010). Quality of communication experience: definition, measurement, and implications for intercultural negotiations. Journal of Applied Psychology, 95(3), 469.

Livingston, B. A. (2014). Bargaining behind the scenes spousal negotiation, labor, and work-family burnout. Journal of Management, 40(4), 949-977.

Lockwood, C. M., \& MacKinnon, D. P. (1998). Bootstrapping the standard error of the mediated effect. In Proceedings of the 23rd annual meeting of SAS Users Group International (pp. 997-1002).

Mannix, E., \& Neale, M. A. (2005). What differences make a difference? The promise and reality of diverse teams in organizations. Psychological Science in the Public Interest, 6(2), 31-55.

Marsh, H. W., \& Hocevar, D. (1985). Application of confirmatory factor analysis to the study of selfconcept: First-and higher order factor models and their invariance across groups. Psychological Bulletin, 97(3), 562.

McIver, J., \& Carmines, E. G. (1981). Unidimensional scaling (Vol. 24). Sage.

Miles, E. W., \& Clenney, E. F. (2010). Gender differences in negotiation: A status characteristics theory view. Negotiation and Conflict Management Research, 3(2), 130-144.

Nelson, N., Bronstein, I., Shacham, R., \& Ben-Ari, R. (2015). The power to oblige: Power, gender, negotiation behaviors, and their consequences. Negotiation and Conflict Management Research, 8(1), 1-24. https://doi.org/10.1111/ncmr.12045

Nunnally, J. C., \& Bernstein, I. H. (1994). Psychometric Theory (McGraw-Hill Series in Psychology) (Vol. 3). McGraw-Hill New York.

Ogliastri, E., \& Quintanilla, C. (2016). Building cross-cultural negotiation prototypes in Latin American contexts from foreign executives' perceptions. Journal of Business Research, 69(2), 452-458.

Olekalns, M., \& Smith, P. (2003). Social motives in negotiation: the relationships between dyad composition, negotiation processes and outcomes. International Journal of Conflict Management, 14(3/4), 233-254. https://doi.org/10.1037//1k122-3514.78.5.889

Ott, D. L., \& Michailova, S. (2018). Cultural Intelligence: A Review and New Research Avenues. International Journal of Management Reviews, 20(1), 99-119.

Pappas, N. (2018). Hotel decision-making during multiple crises: A chaordic perspective. Tourism 
Management, 68, 450-464.

Paulhus, D. L. (1991). Measurement and control of response bias. In J. P. Robinson, P. R. Shaver, \& L. S. Wrightsman (Eds.), Measures of social psychological attitudes, Vol. 1. Measures of personality and social psychological attitudes (pp. 17-59). San Diego, CA, US: Academic Press.

Podsakoff, P. M., MacKenzie, S. B., Lee, J.-Y., \& Podsakoff, N. P. (2003). Common method biases in behavioral research: a critical review of the literature and recommended remedies. Journal of Applied Psychology, 88(5), 879.

Preacher, K. J., \& Hayes, A. F. (2004). SPSS and SAS procedures for estimating indirect effects in simple mediation models. Behavior Research Methods, Instruments, \& Computers, 36(4), 717-731.

Preacher, K. J., Rucker, D. D., \& Hayes, A. F. (2007). Addressing moderated mediation hypotheses: Theory, methods, and prescriptions. Multivariate Behavioral Research, 42(1), 185-227.

Pruitt, D. G., \& Rubin, J. Z. (1986). Social conflict: Escalation, impasse, and resolution. Reding, MA: Addision-Wesley.

Remhof, S., Gunkel, M., \& Schlaegel, C. (2014). Goodbye Germany! The influence of personality and cognitive factors on the intention to work abroad. The International Journal of Human Resource Management, 25(16), 2319-2343.

Ridgeway, C. L. (2001). Gender, status, and leadership. Journal of Social Issues, 57(4), 637-655.

Rivers, C., \& Volkema, R. (2013). East-West differences in "tricky" tactics: A comparison of the tactical preferences of Chinese and Australian negotiators. Journal of Business Ethics, 115(1), 17-31.

Saorín-Iborra, M. C., \& Cubillo, G. (2016). Influence of Time Pressure on the Outcome of Intercultural Commercial Negotiations. Journal of Promotion Management, 22(4), 511-525. https://doi.org/10.1080/10496491.2016.1190224

Schermelleh-Engel, K., Moosbrugger, H., \& Müller, H. (2003). Evaluating the fit of structural equation models: Tests of significance and descriptive goodness-of-fit measures. Methods of Psychological Research Online, 8(2), 23-74.

Schwartz, S. H. (2006). A theory of cultural value orientations: Explication and applications. Comparative Sociology, 5(2), 137-182.

Sharma, S., Bottom, W. P., \& Elfenbein, H. A. (2013). On the role of personality, cognitive ability, and emotional intelligence in predicting negotiation outcomes A meta-analysis. Organizational Psychology Review, 3(4), 293-336.

Sobel, M. E. (1982). Asymptotic confidence intervals for indirect effects in structural equation models. Sociological Methodology, 13, 290-312.

Tabachnick, B. G., \& Fidell, L. S. (2007). Using multivariate statistics. Allyn \& Bacon/Pearson Education.

Traavik, L. E. M. (2011). Is bigger better? Dyadic and multiparty integrative negotiations. International Journal of Conflict Management, 22(2), 190-210. https://doi.org/10.1108/10444061111126701 
Triandis, H. C. (2006). Cultural intelligence in organizations. Group \& Organization Management, 31(1), $20-26$.

Tu, Y.-T. (2014). Cross-cultural equivalence and latent mean differences of the Negotiation Style Profile (NSP-12) in Taiwan and US managers. International Journal of Intercultural Relations, 43(PB), 156164. https://doi.org/10.1016/j.ijintrel.2014.08.001

Tversky, A., \& Kahneman, D. (1974). Judgment Under Uncertainty: Heuristics and Biases. Science, 185, 1124-31. https://doi.org/10.1126/science.185.4157.1124

Vander Elst, T., Van den Broeck, A., De Cuyper, N., \& De Witte, H. (2014). On the reciprocal relationship between job insecurity and employee well-being: Mediation by perceived control? Journal of Occupational and Organizational Psychology, 87(4), 671-693.

Vieregge, M., \& Quick, S. (2011). Cross-cultural negotiations revisited. Cross Cultural Management, 18(3), 313-326. https://doi.org/10.1108/13527601111152842

Vlajčić, D., Caputo, A., Marzi, G., \& Dabić, M. (2018). Expatriates managers' cultural intelligence as promoter of knowledge transfer in multination companies. Journal of Business Research. https://doi.org/10.1016/j.jbusres.2018.01.033

Voorhees, C. M., Brady, M. K., Calantone, R., \& Ramirez, E. (2016). Discriminant validity testing in marketing: an analysis, causes for concern, and proposed remedies. Journal of the Academy of Marketing Science, 44(1), 119-134.

Walters, A. E., Stuhlmacher, A. F., \& Meyer, L. L. (1998). Gender and negotiator competitiveness: A metaanalysis. Organizational Behavior and Human Decision Processes, 76(1), 1-29.

Warner, S. L. (1965). Randomized response: A survey technique for eliminating evasive answer bias. Journal of the American Statistical Association, 60(309), 63-69.

Wheaton, B., Muthen, B., Alwin, D. F., \& Summers, G. F. (1977). Assessing reliability and stability in panel models. Sociological Methodology, 8, 84-136.

Williams, J. E., \& Best, D. L. (1982). Measuring sex stereotypes. A thirty-nation study. Beverly Hills. Beverly Hills, CA: Sage.

Yoo, B., Donthu, N., \& Lenartowicz, T. (2011). Measuring Hofstede's five dimensions of cultural values at the individual level: Development and validation of CVSCALE. Journal of International Consumer Marketing, 23(3-4), 193-210. 


\section{Figures}

Figure 1. Theoretical and Study model showing relationship between Variables.

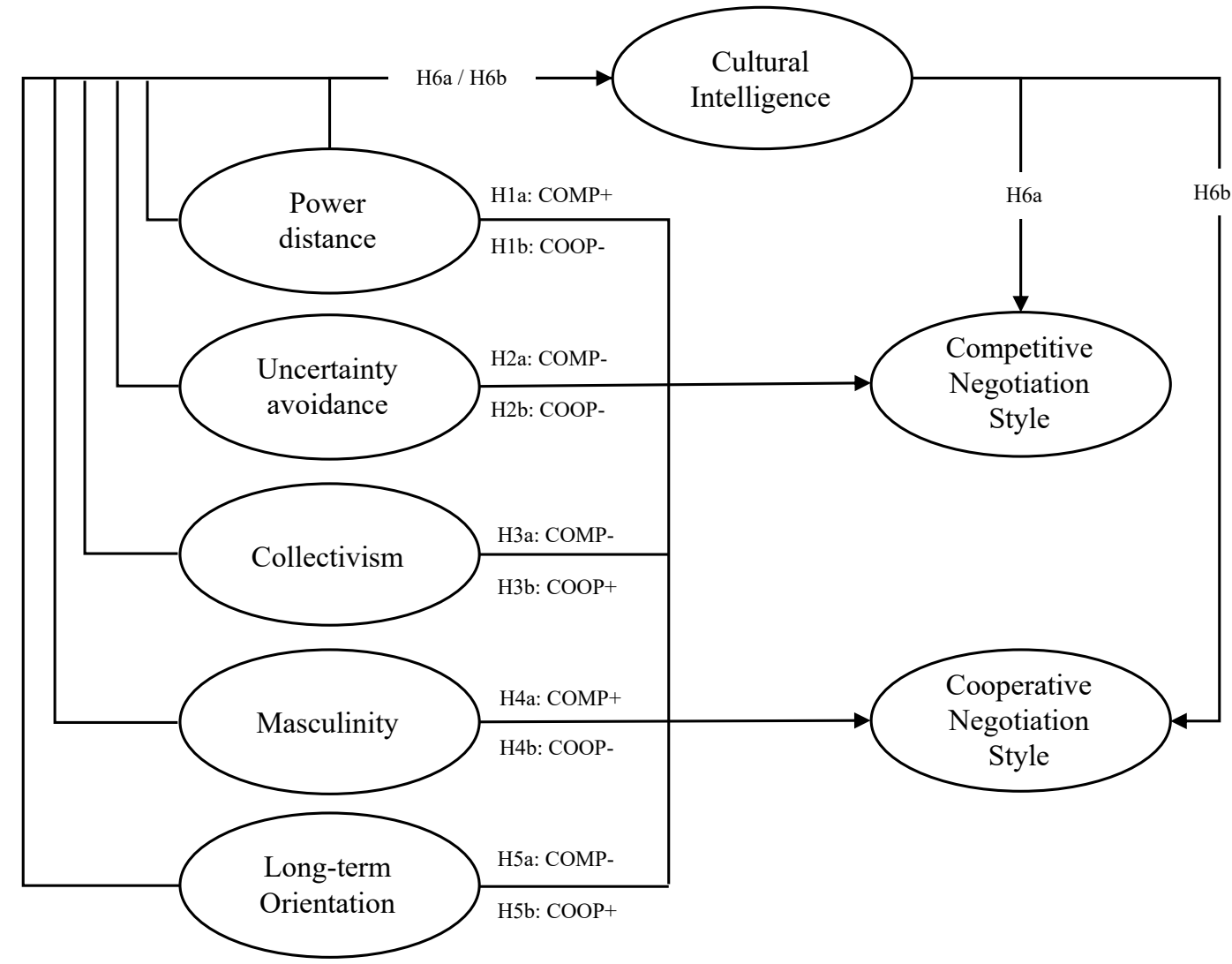

Notes: Hypotheses 1 to 5 are related to the direct relationships of the five Cultural Values and Orientations (CVO) to the two Negotiation Styles (COMP and COOP). Hypotheses $6 \mathrm{a}-\mathrm{b}$ are the mediating effects of the $2^{\text {nd }}$ order Cultural Intelligence (CQ) variable -and the two Negotiation Styles variables. 
Figure 2. The Conceptual and Hypothesis Testing Model

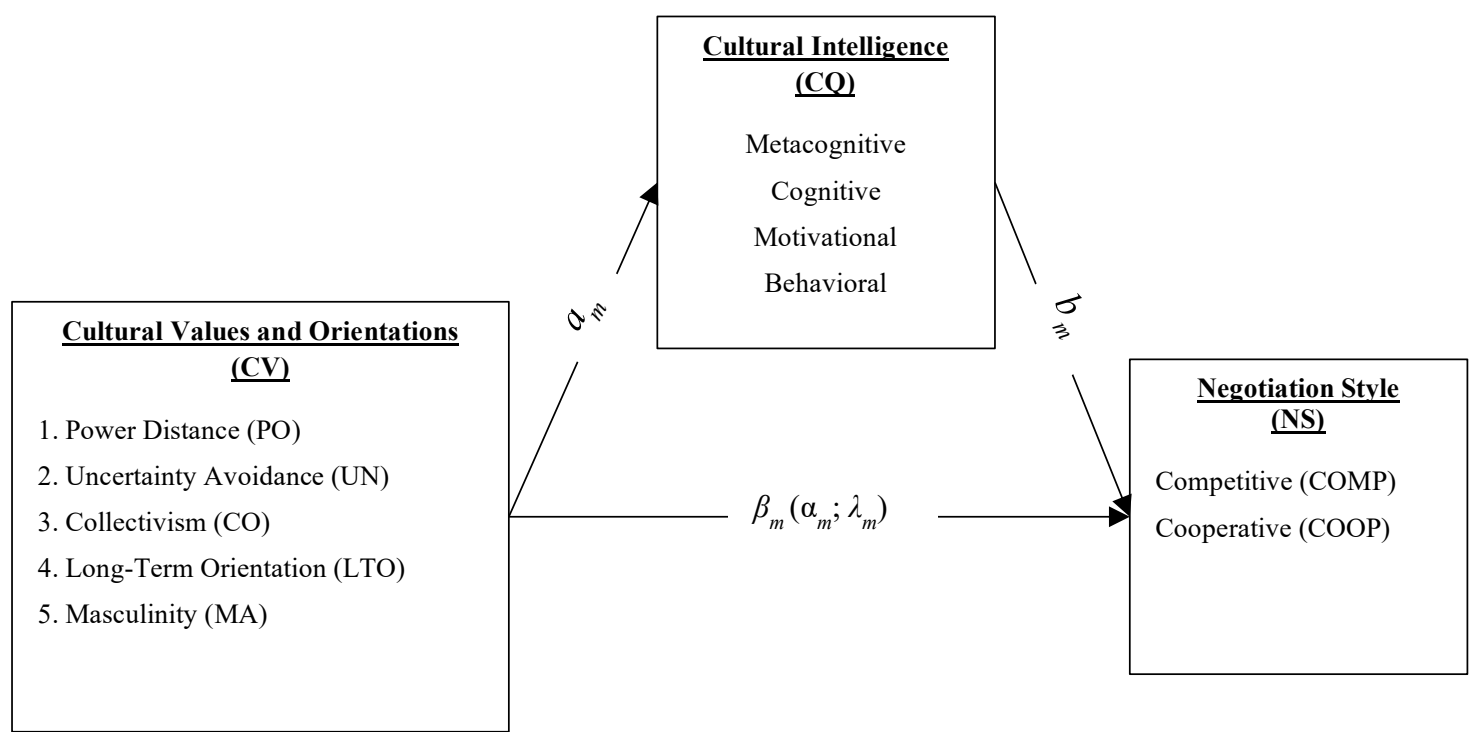

Note: $\beta_{m}$ and $a_{m}$ are the coefficients of the CVs (with $m$ taking the values of $1-5$ for the respective $\mathrm{CVs}$, PO; UN; CO; LTO; MA); and $\alpha_{m}$ and $\lambda_{m}$ are the specific coefficients of Competitive and Cooperative respectively. $b_{m}$ is the coefficient for the relationship between CQ and NS. 
Figure 3. Results of Structural Model using Bootstrapping

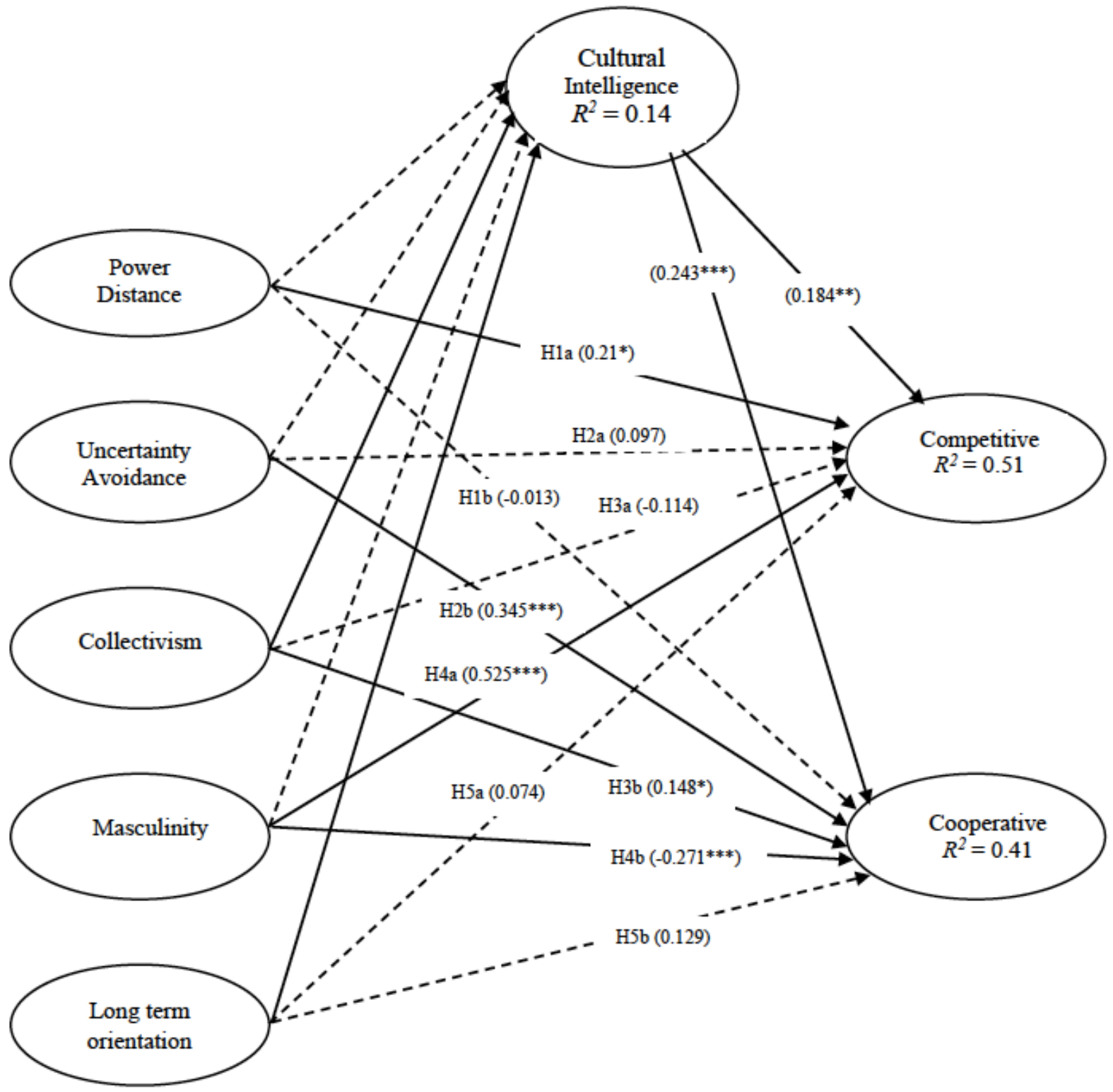

Note: ${ }^{*} p<0.05 ; * * p<0.01 ;{ }^{* * *} p<0.001$. Broken lines represent the unsupported hypotheses or non-significant relationships. Standardized coefficients are in the parenthesis. Also for simplicity $\mathrm{H} 6 \mathrm{a} / \mathrm{b}$ are not represented in this figure, but this is seen by the full lines from the Collectivism and Long-Term Orientation through the mediator (Cultural Intelligence) to the two Negotiation styles. 


\section{Tables}

Table 1. Sample characteristics.

\begin{tabular}{|c|c|c|c|}
\hline Variable & Contents & No. of Samples & Percentage (\%) \\
\hline \multirow[t]{2}{*}{ Gender* } & Male & 187 & 53.3 \\
\hline & Female & 215 & 46.4 \\
\hline \multirow{2}{*}{ Nationality } & UK & 162 & 40.2 \\
\hline & Other** & 241 & 49.8 \\
\hline \multirow[t]{2}{*}{ Ethnicity } & White & 255 & 63.3 \\
\hline & Other & 148 & 36.7 \\
\hline \multirow[t]{2}{*}{ Religion } & Christian & 134 & 33.0 \\
\hline & Other & 80 & 21.1 \\
\hline \multirow[t]{2}{*}{ University degree } & Yes & 307 & 76.2 \\
\hline & No & 96 & 23.8 \\
\hline Variable & Mean & Median & S.D. \\
\hline$\overline{\text { Age }}$ & 34.4 & 32.0 & 9.6 \\
\hline Working experience & 12.4 & 10.0 & 9.6 \\
\hline
\end{tabular}

Table 2. Evaluation of First Order Constructs.

\begin{tabular}{lllll}
\hline $\begin{array}{l}\text { First order } \\
\text { constructs }\end{array}$ & Number of Items & $\begin{array}{l}\text { Cronbach's } \\
\text { Alpha }\end{array}$ & $\begin{array}{l}\text { Composite } \\
\text { Reliability }\end{array}$ & AVE \\
\hline Power Distance & 5 & 0.77 & 0.77 & 0.40 \\
Uncertainty Avoidance & 5 & 0.75 & 0.76 & 0.39 \\
Collectivism & 6 & 0.83 & 0.83 & 0.46 \\
Masculinity & 4 & 0.79 & 0.79 & 0.49 \\
Long-Term Orientation & 3 & 0.73 & 0.76 & 0.48 \\
Metacognitive CQ & 4 & 0.86 & 0.86 & 0.61 \\
Cognitive CQ & 6 & 0.89 & 0.89 & 0.57 \\
Motivational CQ & 5 & 0.85 & 0.87 & 0.57 \\
Behavioral CQ & 5 & 0.86 & 0.87 & 0.57 \\
Cooperative NS & 8 & 0.81 & 0.79 & 0.33 \\
Competitive NS & 8 & 0.76 & 0.77 & 0.30 \\
\hline
\end{tabular}

Note: $\mathrm{CQ}=$ cultural intelligence; $\mathrm{NS}=$ negotiation style.

Table 3. Evaluation of multi-dimensional constructs.

\begin{tabular}{lccccccc}
\hline Construct & $\mathrm{X}^{2}$ & $\mathrm{df}$ & $\begin{array}{c}\text { CMIN/df } \\
\left(X^{2} / d f\right)\end{array}$ & $\mathrm{p}$ & CFI & RMSEA & SRMR \\
\hline Cultural values & 481.19 & 220 & 2.187 & 0.136 & 0.91 & 0.054 & 0.065 \\
Cultural intelligence & 357.86 & 164 & 2.182 & 0.176 & 0.96 & 0.053 & 0.054 \\
Negotiation style & 231.98 & 98 & 2.367 & 0.077 & 0.91 & 0.054 & 0.063 \\
\hline
\end{tabular}

Note: Cultural Intelligence is a second-order construct 
Table 4. Correlation Matrix and Descriptive Statistics $(n=403)$.

\begin{tabular}{|c|c|c|c|c|c|c|c|c|c|c|c|c|}
\hline & & 1 & 2 & 3 & 4 & 5 & 6 & 7 & 8 & 9 & 10 & 11 \\
\hline 1 & Power distance & .632 & & & & & & & & & & \\
\hline 2 & Uncertainty avoidance & .017 & .624 & & & & & & & & & \\
\hline 3 & Collectivism & $.267 * *$ & $.170 *$ & .678 & & & & & & & & \\
\hline 4 & Masculinity & $.523^{* *}$ & $.125^{*}$ & $.223 * *$ & .700 & & & & & & & \\
\hline 5 & Long term orientation & -.013 & $.513 * *$ & $.331 * *$ & .049 & .693 & & & & & & \\
\hline 6 & Metacognitive CQ & -.075 & $.277 * *$ & $.171^{*}$ & .049 & $.281 * *$ & .781 & & & & & \\
\hline 7 & Cognitive CQ & $.214^{*}$ & .055 & $.199 *$ & $.201 * *$ & $.140 * *$ & $.493 *$ & .755 & & & & \\
\hline 8 & Motivational CQ & $-.114 *$ & .093 & $.137^{*}$ & $-.111 *$ & $.164 * *$ & $.520 * *$ & $.520 * *$ & .755 & & & \\
\hline 9 & Behavioral CQ & .003 & $.141 *$ & $.150^{*}$ & .002 & $.174 * *$ & $.616^{* *}$ & $.477 * *$ & $.468 * *$ & .755 & & \\
\hline 10 & Competitive NS & $.413 * *$ & $.208 * *$ & $.175^{* *}$ & $.503 * *$ & $.161 * *$ & $.171^{* *}$ & $.237 * *$ & .007 & .083 & .574 & \\
\hline \multirow[t]{3}{*}{11} & Cooperative NS & -.090 & $.369^{* *}$ & $.206^{* *}$ & $-.142 * *$ & $.379 * *$ & $.316^{* *}$ & $.166^{* *}$ & $.272 * *$ & $.193 * *$ & .027 & .548 \\
\hline & Mean & 1.97 & 4.09 & 3.23 & 2.21 & 4.20 & 3.81 & 2.88 & 3.74 & 3.44 & 2.78 & 3.96 \\
\hline & Standard Deviation & 0.73 & 0.57 & 0.71 & 0.96 & 0.62 & 0.79 & 0.89 & 0.81 & 0.86 & 0.72 & 0.57 \\
\hline
\end{tabular}

Note: ${ }^{*} \mathrm{p}<0.05 ;{ }^{*} \mathrm{p}<0.01 ; * * * \mathrm{p}<0.001 ; \mathrm{SD}=$ Standard Deviation; Square-root of AVEs are in the diagonals.

Table 5. Summary of Hypotheses Test Results with Cultural Intelligence (CQ) as Mediator.

\begin{tabular}{|c|c|c|c|c|c|c|c|}
\hline $\begin{array}{l}\text { Hypothesis } \\
\text { (direction) }\end{array}$ & Independent Variable & & $\begin{array}{c}\text { Dependent } \\
\text { Variable }\end{array}$ & Test Results & Direct Effects & $\begin{array}{l}\text { Indirect } \\
\text { Effects }\end{array}$ & $\begin{array}{c}\text { Type of } \\
\text { Mediation }\end{array}$ \\
\hline $\mathrm{H1a}(+)$ & Power distance & $\overline{--->}$ & Competitive & Supported & $\alpha_{1}=0.21^{*}$ & $\gamma_{l}=-0.012$ & No \\
\hline H3a (-) & Collectivism & $--->$ & Competitive & Not Supported & $\alpha_{3}=-0.114$ & $\gamma_{3}=0.033^{*}$ & Full \\
\hline $\mathrm{H} 4 \mathrm{a}(+)$ & Masculinity & $--->$ & Competitive & Supported & $\alpha_{4}=0.524 * * *$ & $\gamma_{4}=-0.005$ & No \\
\hline $\mathrm{H} 2 \mathrm{~b}(+)$ & Uncertainty avoidance & $--->$ & Cooperative & Supported & $\lambda_{2}=0.345^{* * *}$ & $\gamma_{2}=0.026$ & No \\
\hline $\mathrm{H} 3 \mathrm{~b}(+)$ & Collectivism & $--->$ & Cooperative & Supported & $\lambda_{3}=0.148^{*}$ & $\gamma_{3}=0.044^{*}$ & Partial \\
\hline H4b (-) & Masculinity & $--->$ & Cooperative & Supported & $\lambda_{4}=-0.271 * * *$ & $\gamma_{4}=-0.006$ & No \\
\hline $\mathrm{H} 5 \mathrm{~b}(+)$ & Long term orientation & $--->$ & Cooperative & Not Supported & $\lambda_{5}=0.129$ & $\gamma_{5}=0.047$ & No \\
\hline
\end{tabular}

Note: ${ }^{*} p<0.05 ;{ }^{* *} p<0.01 ;{ }^{* * *} p<0.001$ 


\section{Appendix A}

Descriptive Statistics showing list of all items used in the survey questionnaire and grouped with their respective constructs and sub-constructs. For all measures $n=403$

Table A.1 - Negotiation Style (the 16-item by Livingston, 2014)

Please rank from 1 (being the lowest) to 5 (being the highest) to what extant you agree with the following statements. When I have a conflict at work, I do the following:

\begin{tabular}{llllll}
\hline Construct & Item & Mean & S. D. & Skewness & Kurtosis \\
\hline & Share and share alike & 3.94 & 0.84 & -0.52 & 0.17 \\
Lying never pays & 3.92 & 1.15 & -0.87 & -0.13 \\
& Equal split is fair & 3.56 & 0.98 & -0.29 & -0.29 \\
& Always give others the benefit of the doubt & 3.63 & 0.99 & -0.52 & -0.10 \\
& Take a problem-solving approach & 4.30 & 0.72 & -1.03 & 1.86 \\
Do unto others as you would have them do unto you & 4.00 & 1.13 & -1.11 & 0.58 \\
& Play fair & 4.27 & 0.78 & -1.04 & 1.22 \\
& Be willing to compromise & 4.07 & 0.77 & -0.91 & 1.77 \\
\hline & Never trust your opponent & 2.81 & 1.15 & 0.27 & -0.69 \\
& Your loss is my gain & 2.35 & 1.07 & 0.58 & -0.15 \\
& The best defence is a good offense & 3.12 & 1.08 & -0.02 & -0.53 \\
& First come, first served & 3.00 & 1.19 & -0.05 & -0.90 \\
& Never lay all your cards on the table & 3.60 & 1.02 & -0.25 & -0.65 \\
& Never make the first offer & 2.84 & 0.99 & 0.23 & -0.16 \\
& An eye for an eye and a tooth for a tooth & 2.21 & 1.18 & 0.80 & -0.19 \\
& Winner take all & 2.33 & 1.17 & 0.57 & -0.54 \\
\hline
\end{tabular}


Table A.2 - Cultural Intelligence (Ang et al, 2007, 20-item CQS scale)

Read each statement and select the response that best describes your capabilities. Select the answer that BEST describes you AS YOU REALLY ARE ( 1 = strongly disagree; 5 = strongly agree)

\begin{tabular}{|c|c|c|c|c|c|}
\hline Construct & Item & Mean & S. D. & Skewness & Kurtosis \\
\hline \multirow{5}{*}{ 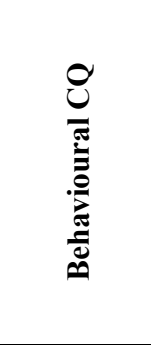 } & $\begin{array}{l}\text { I change my verbal behaviour (e.g., accent, tone) when a cross- } \\
\text { cultural interaction requires it. }\end{array}$ & 3.50 & 1.14 & -0.55 & -0.41 \\
\hline & $\begin{array}{l}\text { I use pause and silence differently to suit different cross-cultural } \\
\text { situations. }\end{array}$ & 3.25 & 1.01 & -0.25 & -0.24 \\
\hline & $\begin{array}{l}\text { I vary the rate of my speaking when a cross-cultural situation } \\
\text { requires it. }\end{array}$ & 3.73 & 0.97 & -0.61 & 0.12 \\
\hline & $\begin{array}{l}\text { I change my nonverbal behaviour when a cross-cultural situation } \\
\text { requires it. }\end{array}$ & 3.53 & 1.05 & -0.52 & -0.31 \\
\hline & $\begin{array}{l}\text { I alter my facial expressions when a cross-cultural interaction } \\
\text { requires it. }\end{array}$ & 3.21 & 1.14 & -0.18 & -0.74 \\
\hline \multirow{6}{*}{ 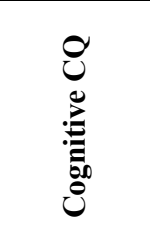 } & I know the legal and economic systems of other cultures. & 2.70 & 1.11 & 0.35 & -0.61 \\
\hline & I know the rules (e.g., vocabulary, grammar) of other languages. & 2.83 & 1.24 & 0.19 & -0.96 \\
\hline & I know the cultural values and religious beliefs of other cultures. & 3.30 & 1.01 & -0.25 & -0.38 \\
\hline & I know the marriage systems of other cultures. & 2.85 & 1.09 & 0.23 & -0.73 \\
\hline & I know the arts and crafts of other cultures. & 2.92 & 1.13 & 0.06 & -0.80 \\
\hline & $\begin{array}{l}\text { I know the rules for expressing nonverbal behaviours in other } \\
\text { cultures. }\end{array}$ & 2.70 & 1.09 & 0.27 & -0.61 \\
\hline \multirow{4}{*}{ 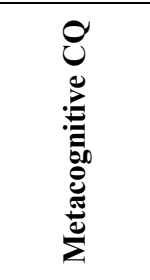 } & $\begin{array}{l}\text { I am conscious of the cultural knowledge I use when interacting } \\
\text { with people with different cultural backgrounds. }\end{array}$ & 3.85 & 0.95 & -0.76 & 0.35 \\
\hline & $\begin{array}{l}\text { I adjust my cultural knowledge as I interact with people from a } \\
\text { culture that is unfamiliar to me. }\end{array}$ & 3.88 & 0.91 & -0.69 & 0.27 \\
\hline & $\begin{array}{l}\text { I am conscious of the cultural knowledge I apply to cross- } \\
\text { cultural interactions. }\end{array}$ & 3.79 & 0.92 & -0.73 & 0.56 \\
\hline & $\begin{array}{l}\text { I check the accuracy of my cultural knowledge as I interact with } \\
\text { people from different cultures. }\end{array}$ & 3.73 & 1.01 & -0.72 & 0.26 \\
\hline \multirow{5}{*}{ 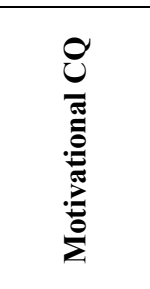 } & I enjoy interacting with people from different cultures. & 4.17 & 0.89 & -0.95 & 0.60 \\
\hline & $\begin{array}{l}\text { I am confident that I can socialize with locals in a culture that is } \\
\text { unfamiliar to me. }\end{array}$ & 3.64 & 1.07 & -0.60 & -0.18 \\
\hline & $\begin{array}{l}\text { I am sure I can deal with the stresses of adjusting to a culture } \\
\text { that is new to me. }\end{array}$ & 3.75 & 0.95 & -0.55 & -0.09 \\
\hline & I enjoy living in cultures that are unfamiliar to me. & 3.38 & 1.17 & -0.33 & -0.73 \\
\hline & $\begin{array}{l}\text { I am confident that I can get accustomed to the shopping } \\
\text { conditions in a different culture. }\end{array}$ & 3.78 & 0.94 & -0.60 & 0.06 \\
\hline
\end{tabular}


Table A.3 - Cultural Values (the Yoo et al, 2011 26-item CVSCALE)

Please rank from 1 (being the lowest) to 5 (being the highest) to what extant you agree with the following statements

\begin{tabular}{|c|c|c|c|c|c|}
\hline Construct & Item & Mean & S. D. & Skewness & Kurtosis \\
\hline \multirow{5}{*}{ 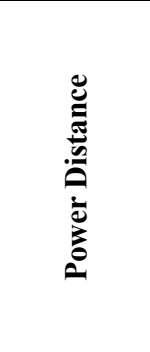 } & $\begin{array}{l}\text { People in higher positions should make most decisions without } \\
\text { consulting people in lower positions. }\end{array}$ & 2.13 & 1.02 & 0.78 & 0.17 \\
\hline & $\begin{array}{l}\text { People in higher positions should not ask the opinions of people in } \\
\text { lower positions too frequently. }\end{array}$ & 2.03 & 0.97 & 0.79 & 0.10 \\
\hline & $\begin{array}{l}\text { People in higher positions should avoid social interaction with } \\
\text { people in lower positions. }\end{array}$ & 1.66 & 1.05 & 1.64 & 1.86 \\
\hline & $\begin{array}{l}\text { People in lower positions should not disagree with decisions by } \\
\text { people in higher positions. }\end{array}$ & 1.86 & 0.99 & 1.11 & 0.68 \\
\hline & $\begin{array}{l}\text { People in higher positions should not delegate important tasks to } \\
\text { people in lower positions. }\end{array}$ & 2.16 & 1.05 & 0.84 & 0.23 \\
\hline \multirow{5}{*}{ 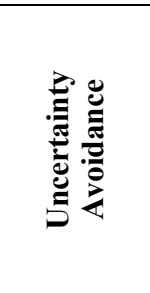 } & $\begin{array}{l}\text { It is important to have instructions spelled out in detail so that I } \\
\text { always know what I'm expected to do. }\end{array}$ & 3.65 & 1.02 & -0.46 & -0.35 \\
\hline & It is important to closely follow instructions and procedures. & 4.06 & 0.79 & -0.52 & -0.05 \\
\hline & $\begin{array}{l}\text { Rules and regulations are important because they inform me of what } \\
\text { is expected of me. }\end{array}$ & 3.97 & 0.81 & -0.72 & 0.66 \\
\hline & Standardized work procedures are helpful. & 4.23 & 0.73 & -0.78 & 0.52 \\
\hline & Instructions for operations are important. & 4.52 & 0.63 & -1.32 & 2.64 \\
\hline \multirow{6}{*}{ 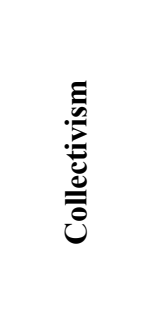 } & Individuals should sacrifice self-interest for the group. & 2.92 & 1.00 & 0.03 & -0.31 \\
\hline & Individuals should stick with the group even through difficulties. & 3.64 & 0.86 & -0.34 & -0.02 \\
\hline & Group welfare is more important than individual rewards. & 3.34 & 0.93 & -0.10 & -0.18 \\
\hline & Group success is more important than individual success. & 3.19 & 1.05 & -0.20 & -0.52 \\
\hline & $\begin{array}{l}\text { Individuals should only pursue their goals after considering the } \\
\text { welfare of the group. }\end{array}$ & 2.99 & 1.00 & 0.04 & -0.40 \\
\hline & Group loyalty should be encouraged even if individual goals suffer. & 3.29 & 0.96 & -0.04 & -0.36 \\
\hline \multirow{4}{*}{ 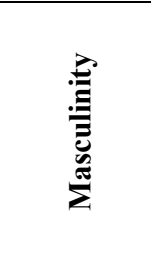 } & $\begin{array}{l}\text { It is more important for men to have a professional career than it is } \\
\text { for women. }\end{array}$ & 1.78 & 1.16 & 1.33 & 0.63 \\
\hline & $\begin{array}{l}\text { Men usually solve problems with logical analysis; women usually } \\
\text { solve problems with intuition. }\end{array}$ & 2.17 & 1.17 & 0.67 & -0.52 \\
\hline & $\begin{array}{l}\text { Solving difficult problems usually requires an active, forcible } \\
\text { approach, which is typical of men. }\end{array}$ & 2.30 & 1.22 & 0.47 & -0.94 \\
\hline & There are some jobs that a man can always do better than a woman. & 2.56 & 1.35 & 0.32 & -1.18 \\
\hline \multirow{6}{*}{ 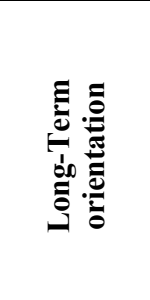 } & Careful management of money (Thrift) & 4.07 & 0.77 & -0.87 & 1.57 \\
\hline & Going on resolutely in spite of opposition (Persistence) & 3.61 & 0.89 & -0.44 & 0.23 \\
\hline & Personal steadiness and stability & 4.13 & 0.76 & -0.46 & -0.21 \\
\hline & Long-term planning & 4.25 & 0.76 & -0.75 & 0.21 \\
\hline & Giving up today's fun for success in the future & 3.16 & 1.03 & -0.11 & -0.43 \\
\hline & Working hard for success in the future & 4.29 & 0.77 & -0.94 & 0.64 \\
\hline
\end{tabular}

